\title{
THE AGRICULTURAL TRAINING NEEDS OF AGRICULTURAL EXTENSION AGENTS REGARDING IMPROVEMENT WHEAT CROP PRODUCTIVITY IN KAFR EL- SHEIKH GOVERNORATE
}

Abd El- Wahab, M. M. ELS.

Agricultural Extension and Rural Development Research Institute, Agricultural Research Center

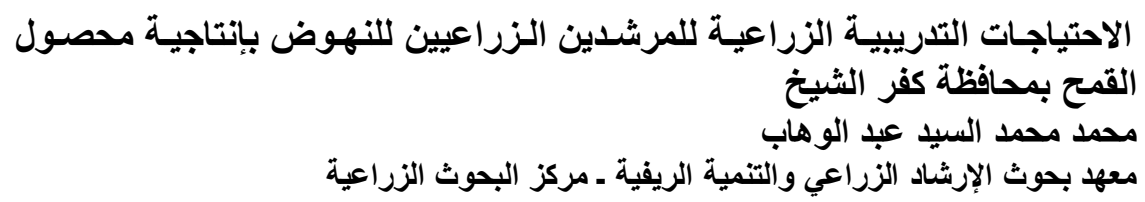

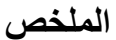

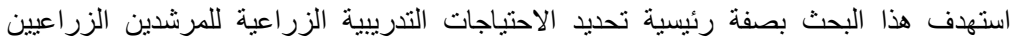

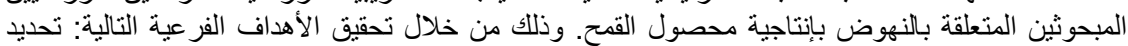

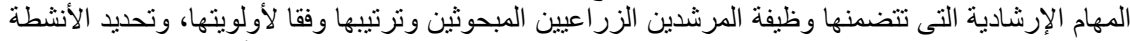

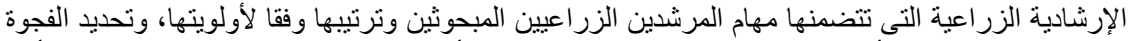

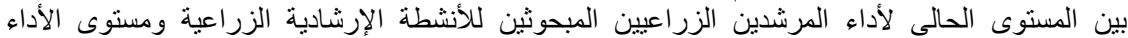

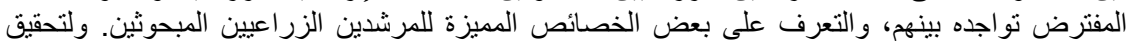

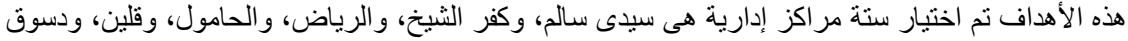

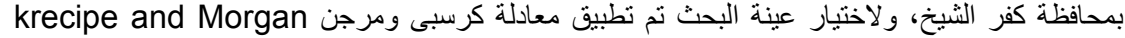

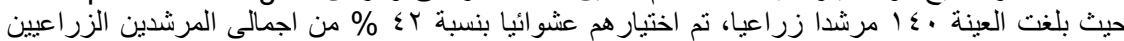

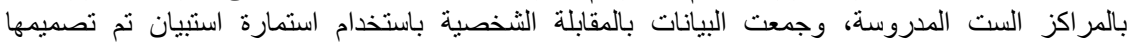

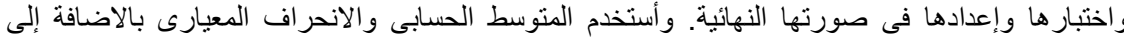

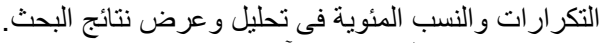

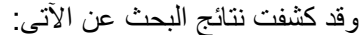

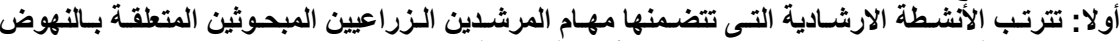

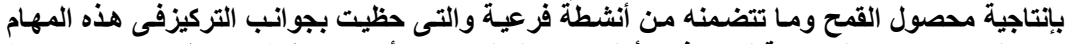

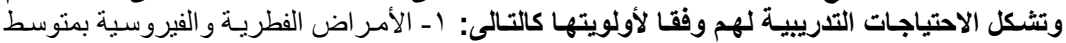

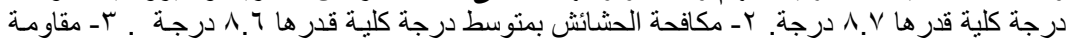

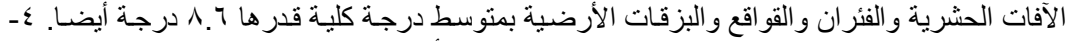

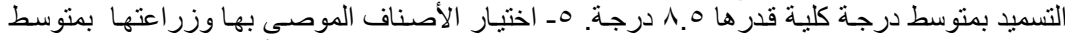

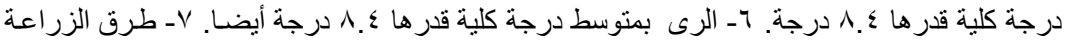

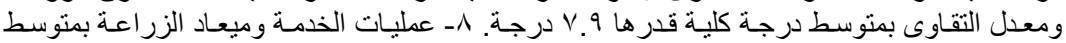

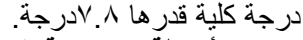

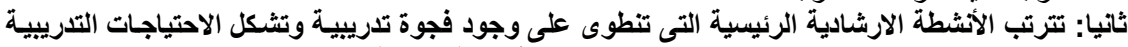

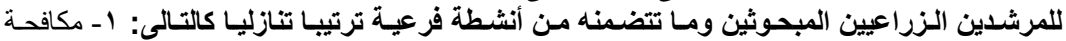

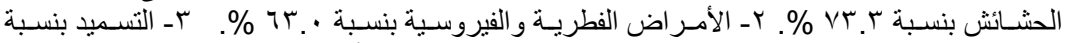

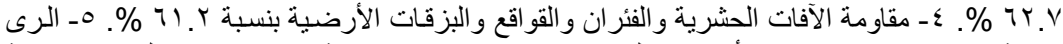

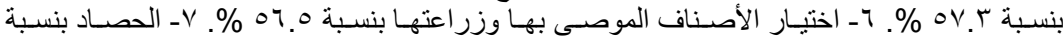

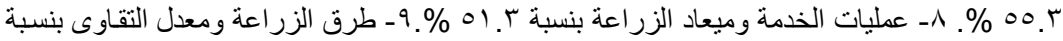
$\% 0 \cdot . \mathrm{V}$

ثالثا: أوضحت النتائج أن ع. 19 \% من المرشدين الزر اعيين المبحوثين من ذوى النشأة الريفية، ومن ثم يعكس

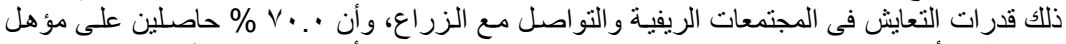

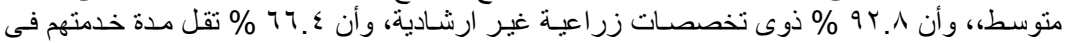


Abd El- Wahab, M. M. ELS.

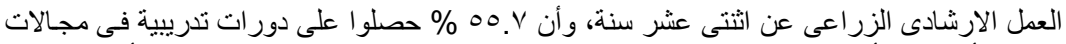

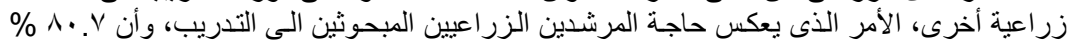

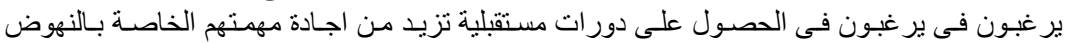
بانتاجية محصول القمح، ولزيادة معلوماتهم وخبر اتهم بما يمكنهم من انجاز المهام الموكولة الئهم بكفاءة وفعالية.

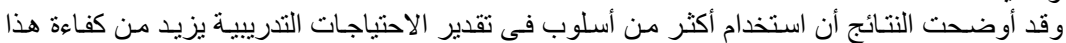

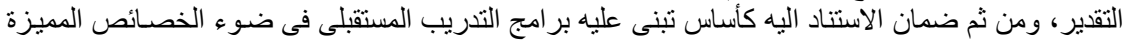

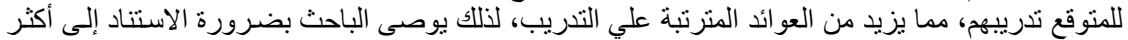

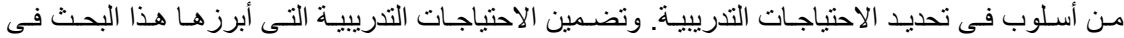

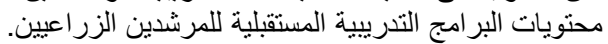

\section{المقدمة والمشكلة البحثية}

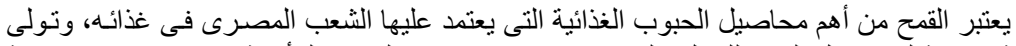

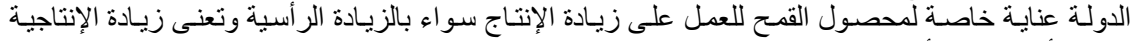

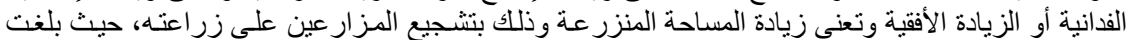

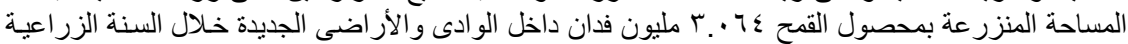

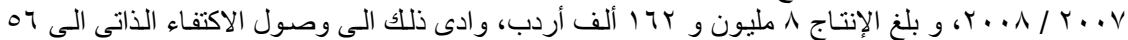

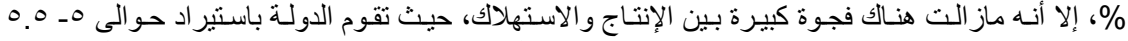

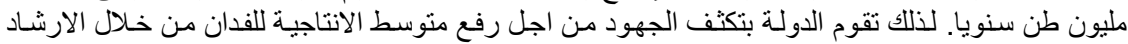

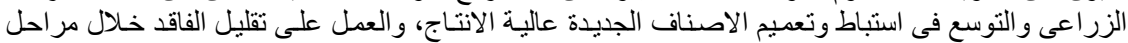

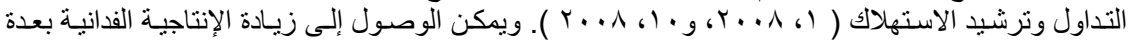

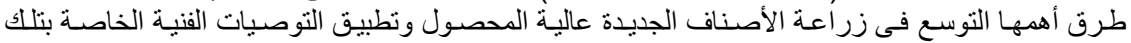

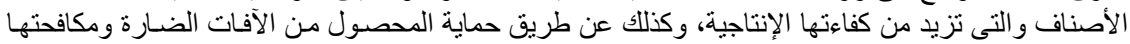

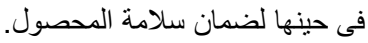
لذللك يقوم الإرشاد الزراعى بدور هام فى رفع كفاءة الإنتاج الزراعى التهى من خلال تثقيف العنصر

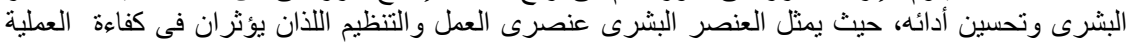

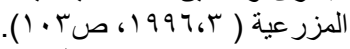

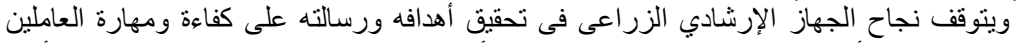

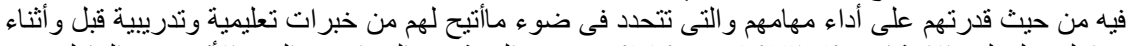

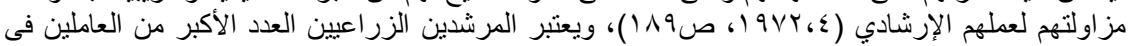

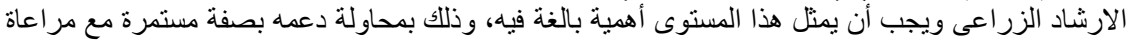

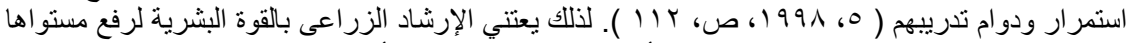

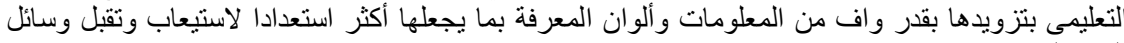

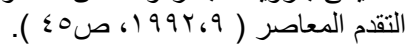

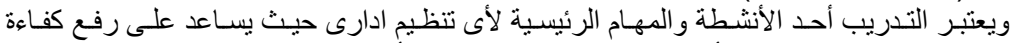

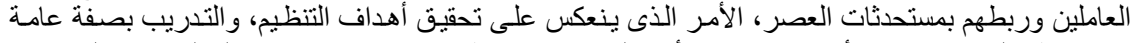

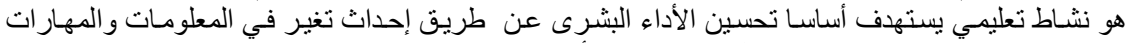

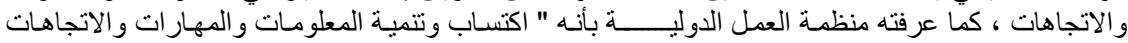

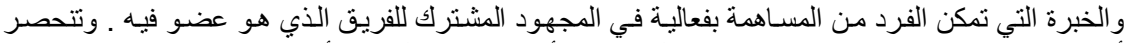

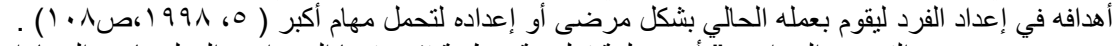

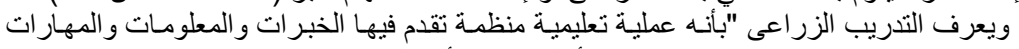

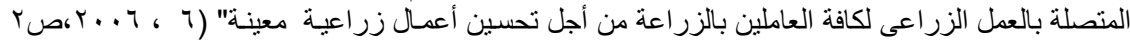

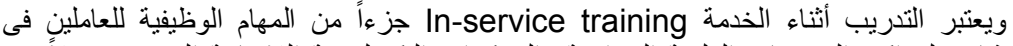

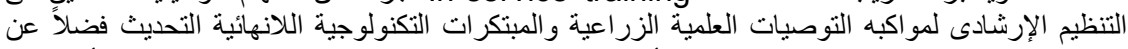

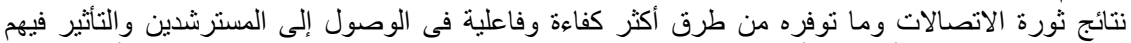

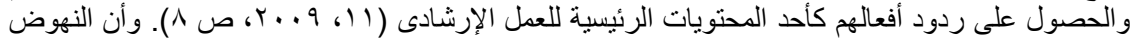




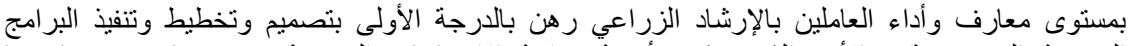

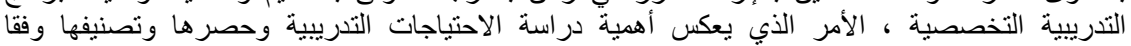

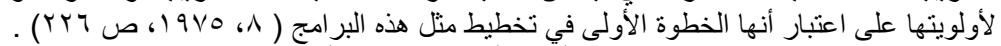

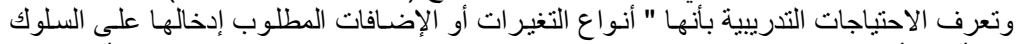

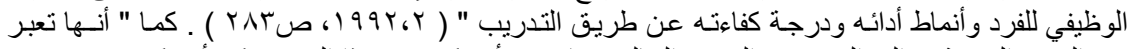

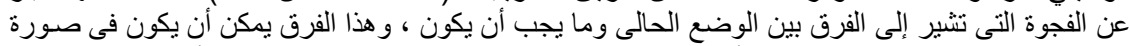

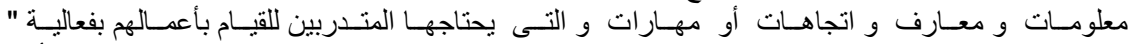

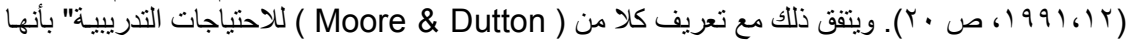

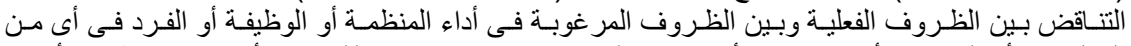

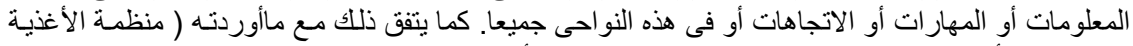

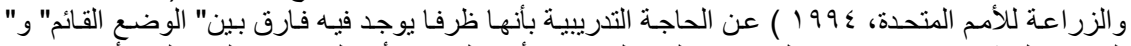

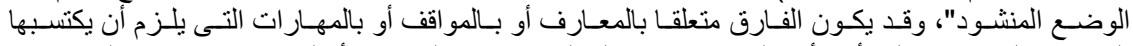

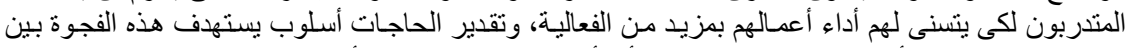

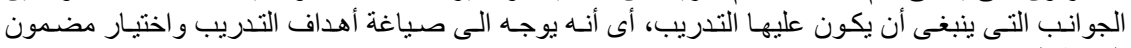

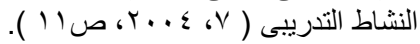

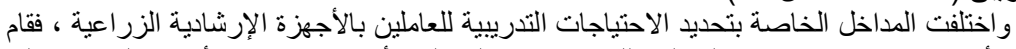

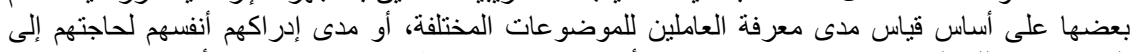

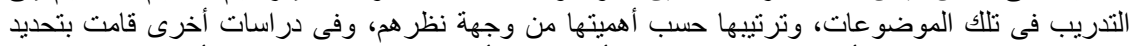

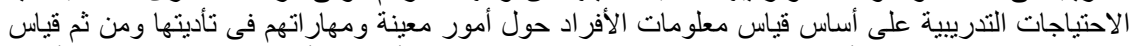

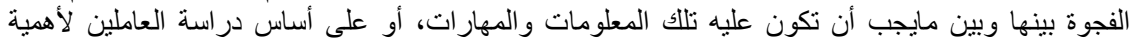

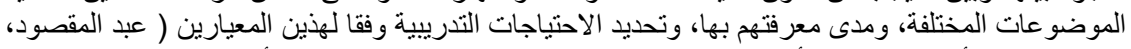

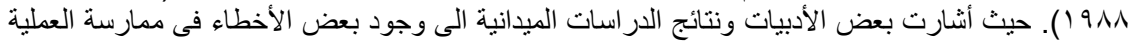

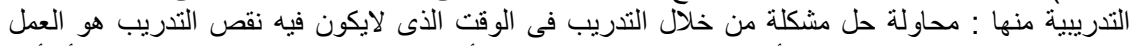

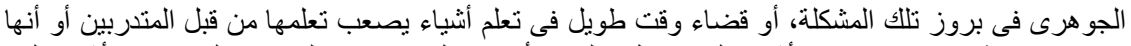

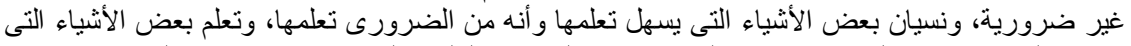

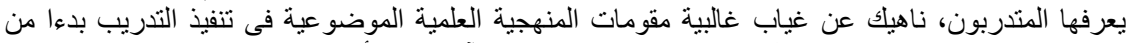

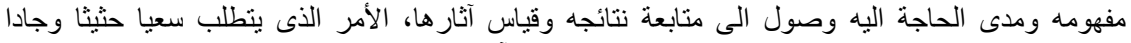

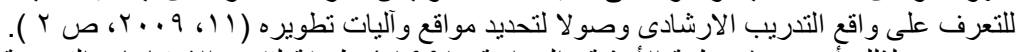

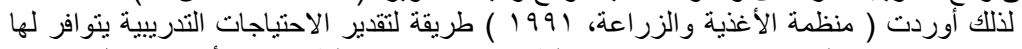

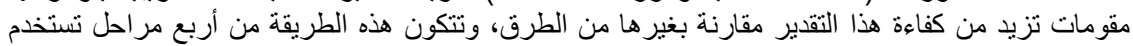

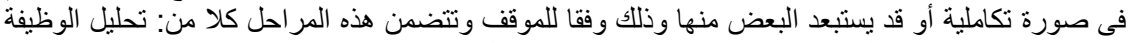

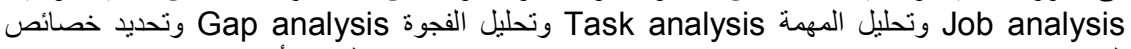
المتدربين Determine Trainees Characteristics وهى تستند إلى ما أورده

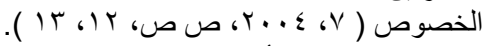

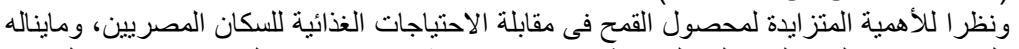

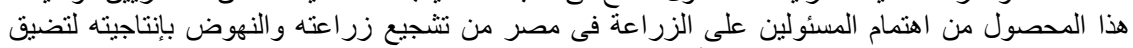

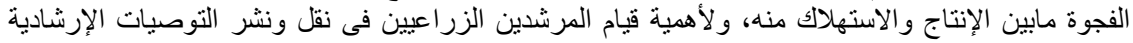

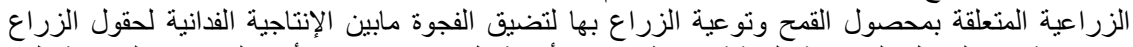

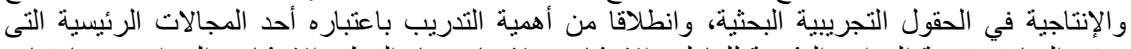

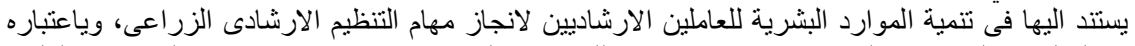

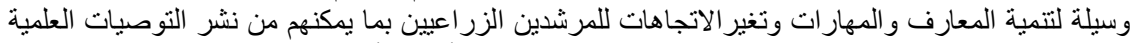

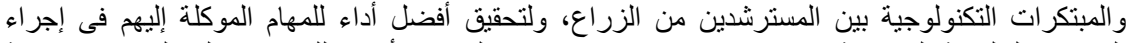

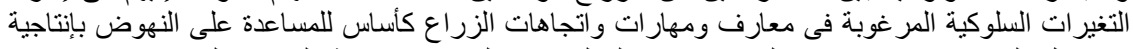

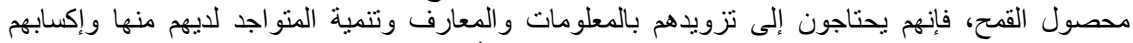

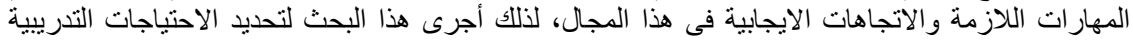

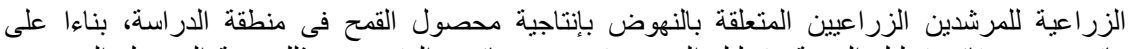

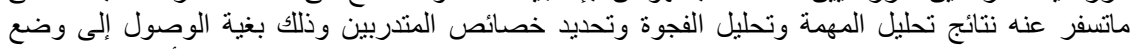

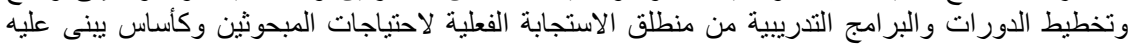


Abd El- Wahab, M. M. ELS.

التدريب، والكثف عن نواحى القصور أو النقص التى أسفرت عنه الطرق الأخرى فى تقدير الاحتياجات

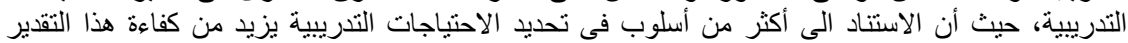

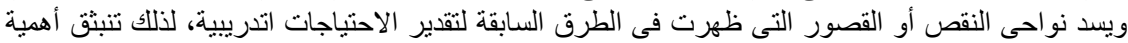

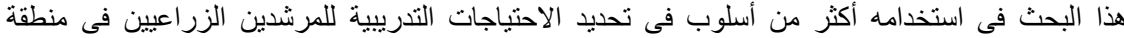

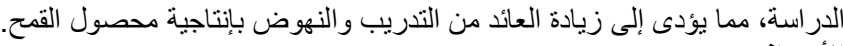

الأهـداف

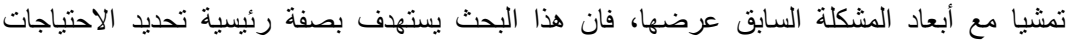

التدريبية الزراعية للمرشدين الزراعبين المبحوثين المتعلقة بالنهوض بإنتاجية محصول القمح فى منطقة

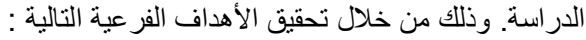

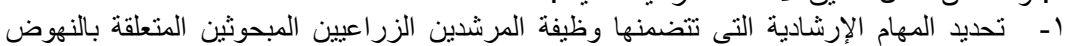

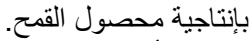

r- تحديد الأنشطة الإرشادية الزراعية التى تتضمنها مهام المرشدين الزراعيين المبحوثين المتعلقة

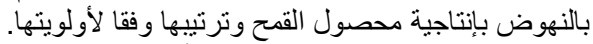

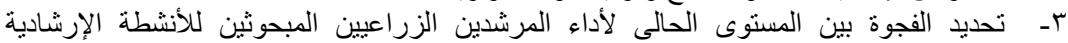

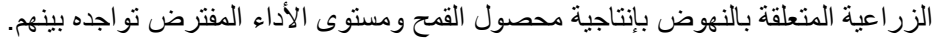
ع - التعرف على بعض الخصائص المميزة للمرشدين الزر اعيين المبحوثين.

\section{الطريقة البحثية}

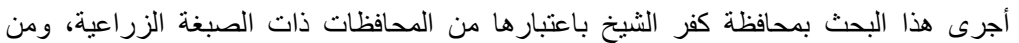

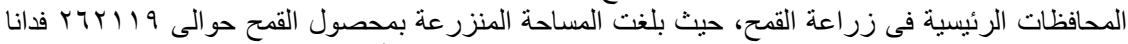

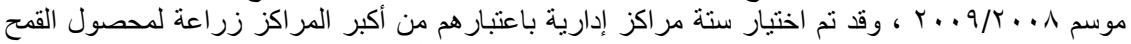

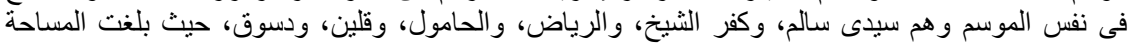

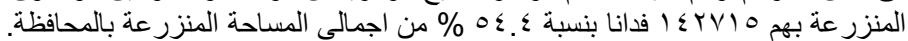

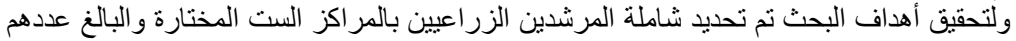

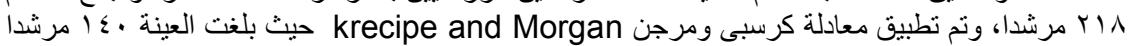

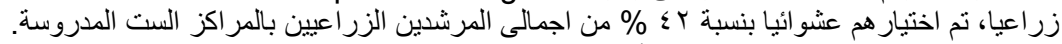

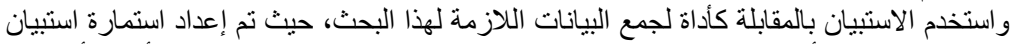

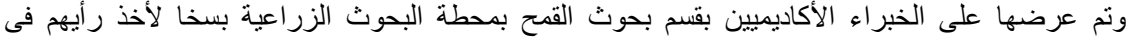

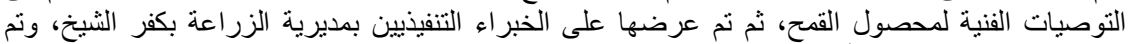

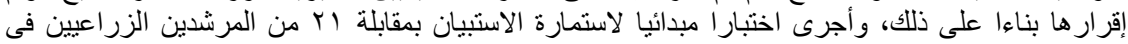

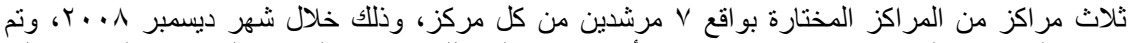

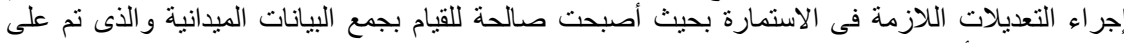

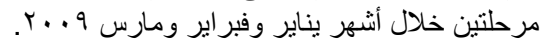
المتغيرات البحثية وتعريفاتها الإجرائية:

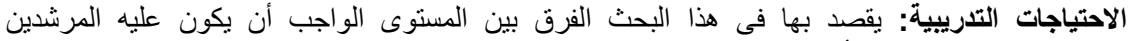

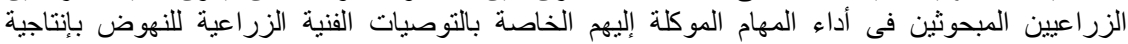

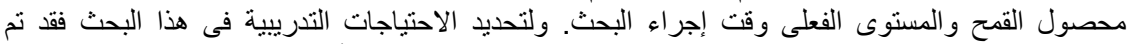

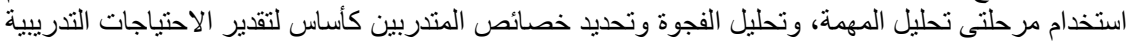

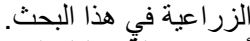

أولا: مرحلةّ تحليل المهمة: لبقة بقدد بها تجزئة المهمة إلى مكوناتها من أنشطة أو عناصر ، حيث تم تحليل مهمة

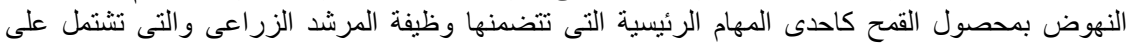

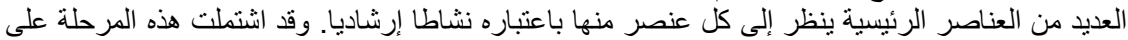

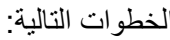

1- تحديد مدى تكرار أداء كل نشاط: ويقصد بها معدل تنفبذ المرشدين الزر اعبين المبحوثين لكل نشاط

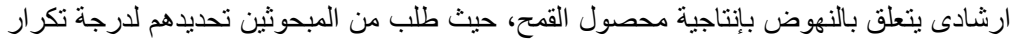

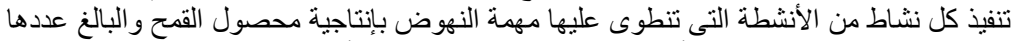

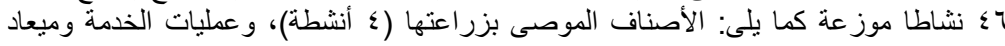




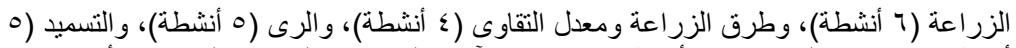

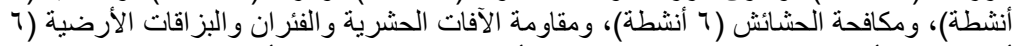

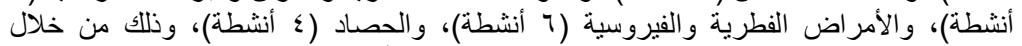

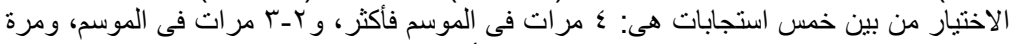

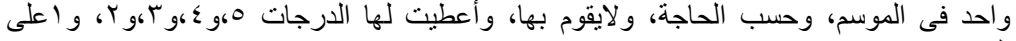
التزتيب.

r- ت تحديد الأهمية النسبية لكل نثاط: ويقصد بها درجة تقدير المرشدين الزراعيين المبحوثين لأهمية

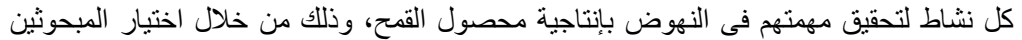

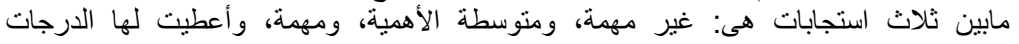

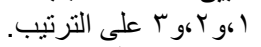
r- تقدير صعوبة تعلم كل نثاط: ويقصد بها النقدير الذانى للمرشدين الزراعيين المبحوثين المتعلق

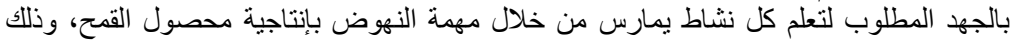

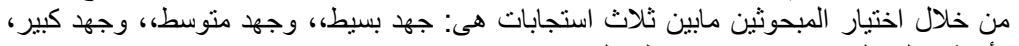

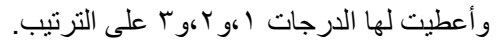

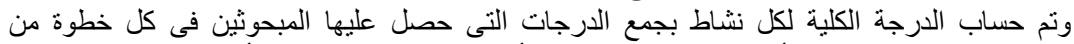
الخطوات السابقة، وبذلك تكون الأنشطة التى حصلت على أعلى الدرجات هى ذات الألى الولوية في التنريب، وتم ترتيبها وفقا لأولويتها.

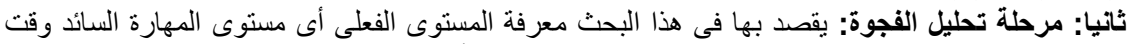

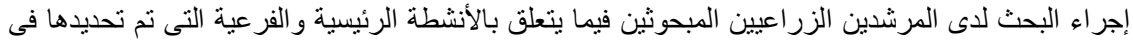
مرحلة تحليل المهمة، وفيما يلى خطوات الزئ تحليل الفجوة:

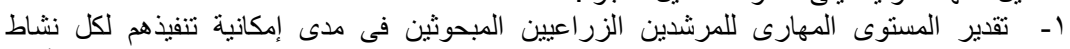

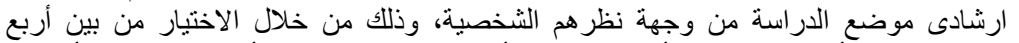

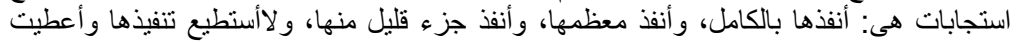

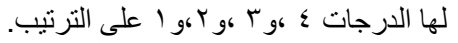
r- ت تقدير الوقت اللازم اللتففيذ من خلال استجابتين هما: أستطيع تنفيذه فى وقت طويل، وأستطيع تنفيذه

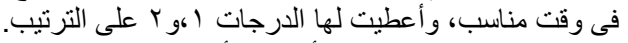

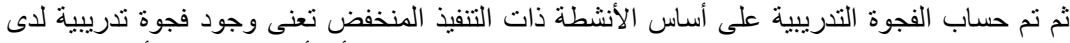

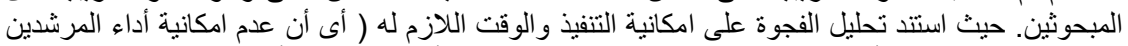

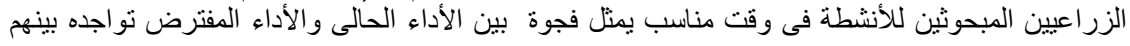

ثالثا: الخصائص المميزة للمرشدين الزراعيين:

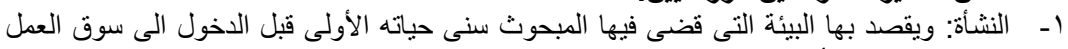
سواء كانت ريفية أم حضرية.

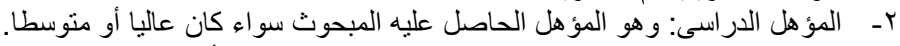

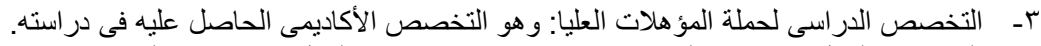

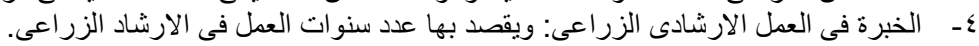

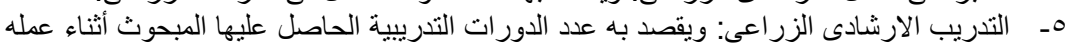

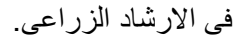
7- التدريب المستقبلى: ويقصد بهاد رغبة المبحوث فى التدريب فى الارشاد الزر اعى بصفة عامة وفى

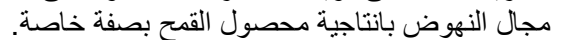
وأستخدم فى تحليل البيانات إحصائيا المتوسط الحسابى والانحر اف المعيات الميارى بالاضافة إلى التكرارات النتائج البحثية ومناقشتها و النسب المئوية لعرض نتائج البحث.

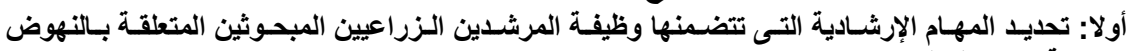

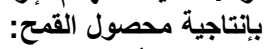

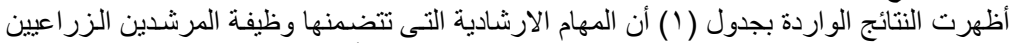

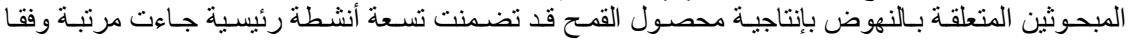


Abd El- Wahab, M. M. ELS.

لمتوسطات الدرجـة الكليـة للقيم المعبرة عن معسايير تحليـل المهمـة الارشـادية المتمنلـة في التكر ار وار والأهميـة

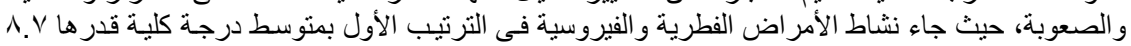

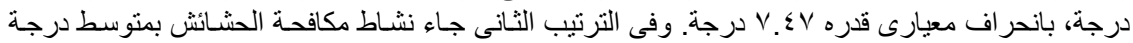

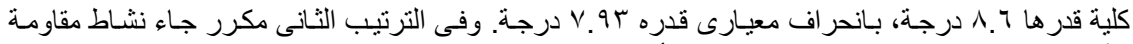

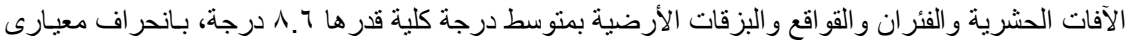

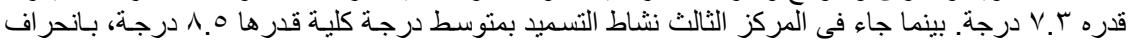

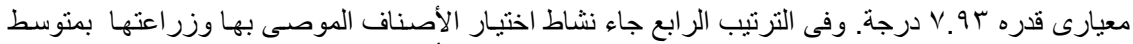

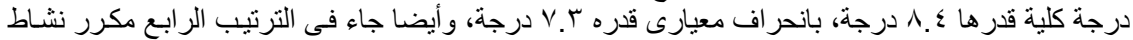

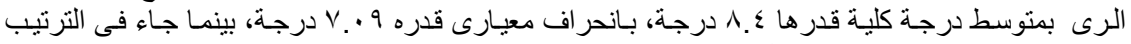

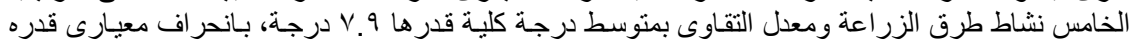

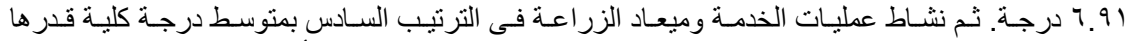

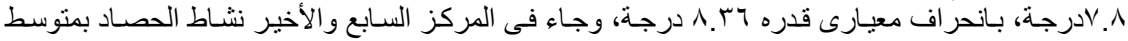

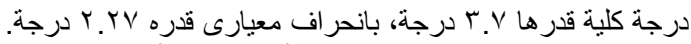

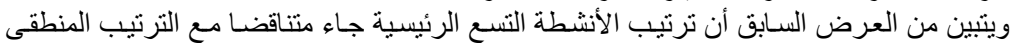

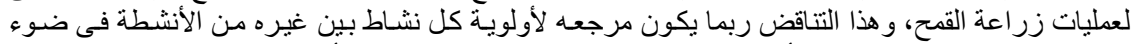

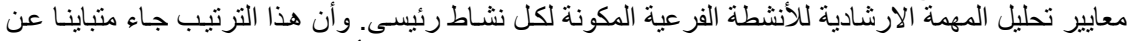

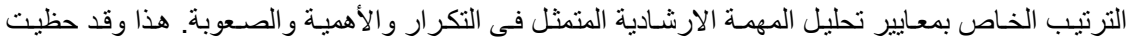

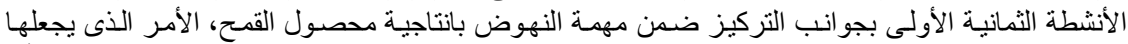

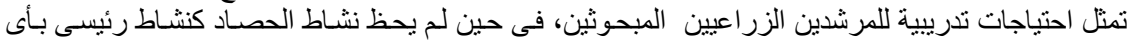
من جوانب التركيز فى مهمة المرشدين الزراعين لاعين المبحوثين، وبالتالى لايمثل احتياجا تدريبيا لديهر.

جدول رقم (1) المتوسـات الحسـابية والانحر افـات المعياريـة للأنشطة الرئيسية المكونـة للمهام الارشـادية

\begin{tabular}{|c|c|c|c|c|c|c|c|c|c|c|}
\hline الثَركيزّ & المعيارى الإن & ترتيب. & |الإنوجنة & & |لدرجة متوسية & زرتيب & الإهنَّة & 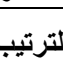 & 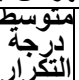 & الأنشطة الارشادية \\
\hline نعم & ะ.9\% & $\varepsilon$ & A. $\varepsilon$ & r & T.r & 1 & r.A & 。 & $r . r$ & 1- اختبار الاصناف الموصى بها \\
\hline نعم & 1.44 & 1 & V.A & $\varepsilon$ & r. 1 & r & T. .7 & 1 & r.r & 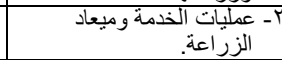 \\
\hline نعم & $0 . r \varepsilon$ & . & v. 9 & r & r. tr & $\varepsilon$ & r.o & T7 & r.r & rا التقاقو الزر اعة ومعدل \\
\hline نعم & $\frac{Y .9}{9}$ & مE & $\Lambda . \varepsilon$ & $35^{2}$ & T.Y & ! & T.A & $\varepsilon$ & T. . & 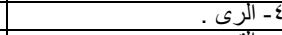 \\
\hline نعم & 7.91 & $r$ & 1.0 & Tा & T.r & 1 & T.A & 1 & r. & 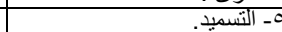 \\
\hline نعم & $\frac{9.9}{9}$ & 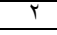 & $\Lambda .7$ & $\begin{array}{ll}5_{1} \\
\end{array}$ & $\begin{array}{r}. T \\
\end{array}$ & ! & T.A & $\Gamma$ & $\Gamma .0$ & 7- مكافحةُ الحشُشأش. \\
\hline نعم & Y.r. & r & 1.7 & r & T.r & r & T.V & r & T. .7 & 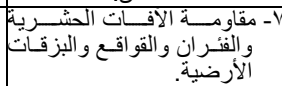 \\
\hline نعم & $Y . \Sigma V$ & 1 & $\Lambda . \mathrm{V}$ & 1 & r. $\varepsilon$ & ام & r.A & r & r.o & 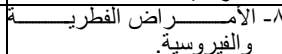 \\
\hline & TRY & V & $r v$ & 0 & 1,1 & 0 & 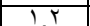 & $\mathrm{v}$ & $1 \leqslant$ & 9- الحصناد \\
\hline
\end{tabular}

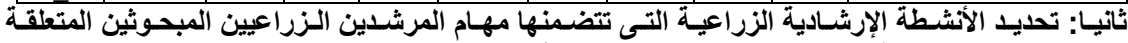

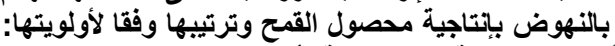

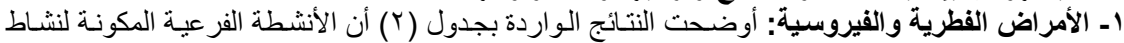

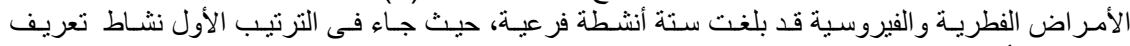

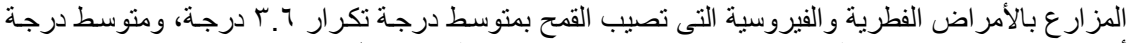

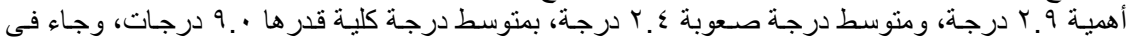

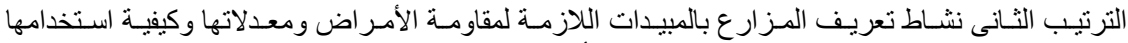

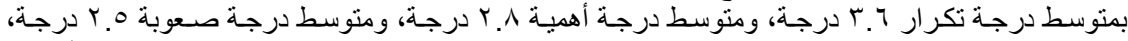

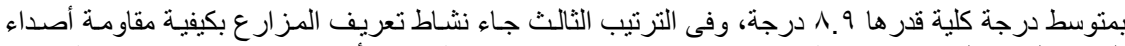

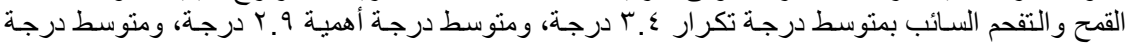

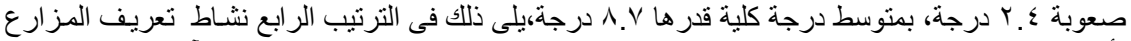

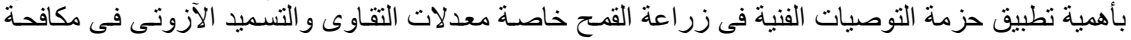




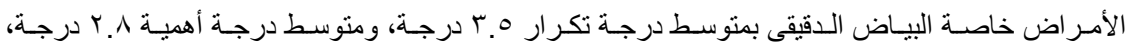

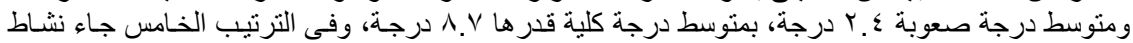

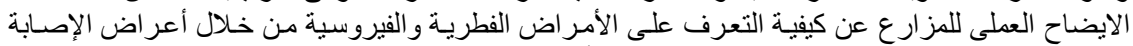

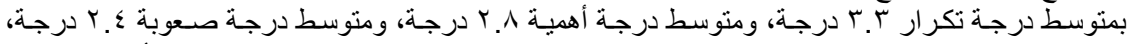

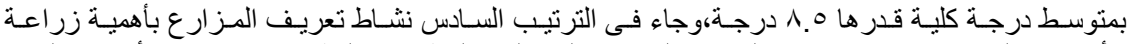

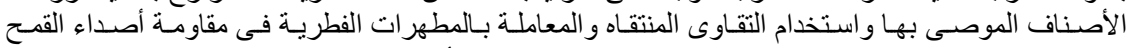

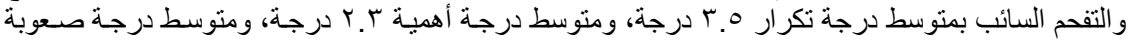

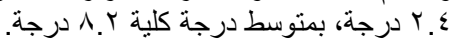

جدول رقم (ץ) المتوسـات الحسـابية والاتحر افـات المعياريـة للأنشـة الفرعيـة المكونـة للمهـام الارشـادية المتعقة بنشاط الأمراض الفطرية وابة والفيرات الفيروسية

\begin{tabular}{|c|c|c|c|c|c|c|c|c|c|}
\hline التركيز & |الترتيب & الدتوسطة & | الترتيب & الصعوبة & الترتيج & متوسطة & الترتيب & متوسط & الأنشطة الارشادية \\
\hline نعم & 1 & १. & r & T.乏 & 1 & r. 9 & 1 & $r .7$ & 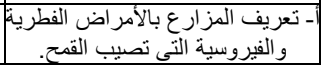 \\
\hline ن نعم & 。 & 1.0 & r & r. $\varepsilon$ & r & r.^ & $\varepsilon$ & r.r & الإصـابة. \\
\hline نعم & r & A.V & r & T.乏 & ام & r.q & r & r. & 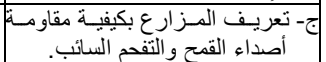 \\
\hline نعم & r & $\wedge .9$ & 1 & r.o & r & r.^ & ام & T. & 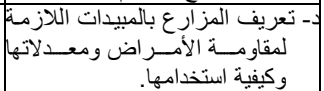 \\
\hline نعم & 7 & A. r & r & r. $\varepsilon$ & $r$ & r. & r & r.o & 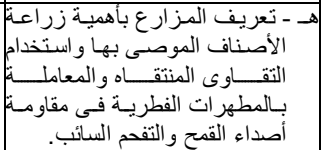 \\
\hline 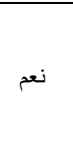 & $\varepsilon$ & ^. $\vee$ & r & r. $\varepsilon$ & r & r.^ & r & r.0 & 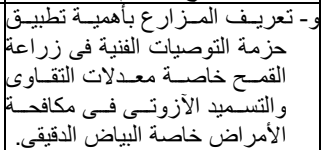 \\
\hline
\end{tabular}

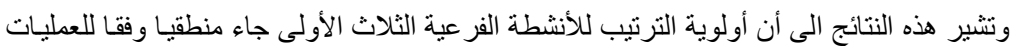

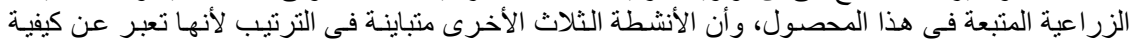

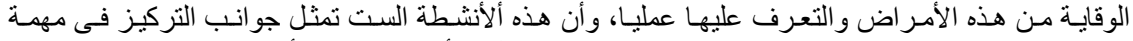

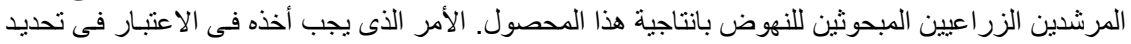

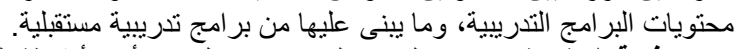

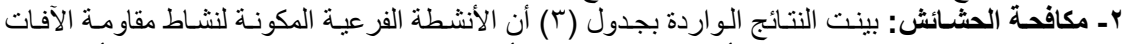

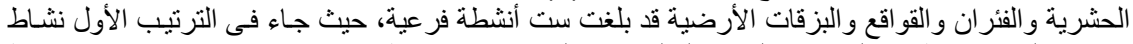

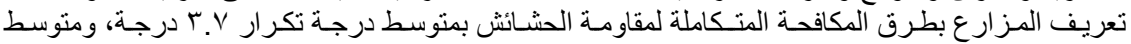

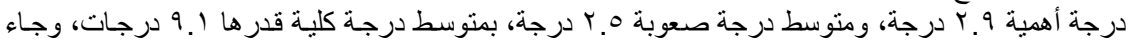

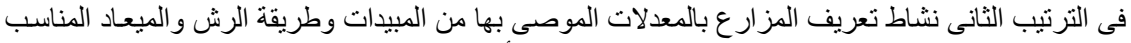

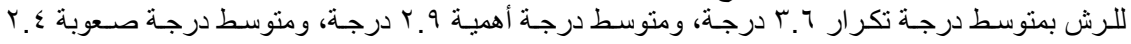

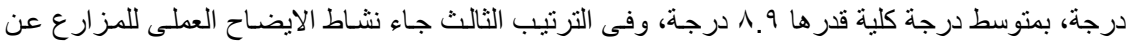

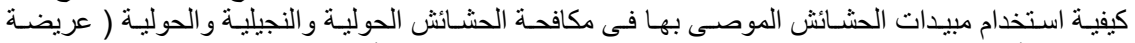

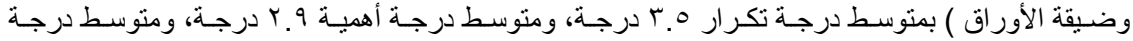

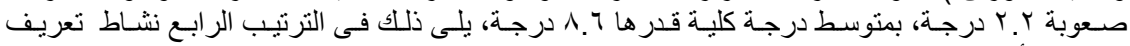

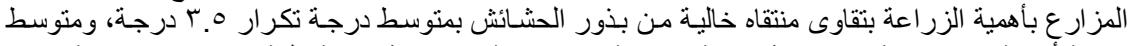

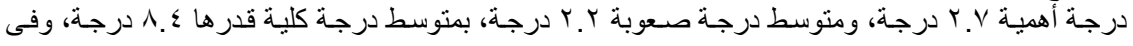


Abd El- Wahab, M. M. ELS.

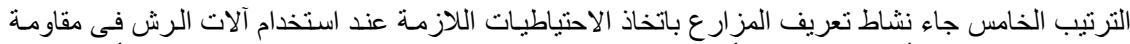

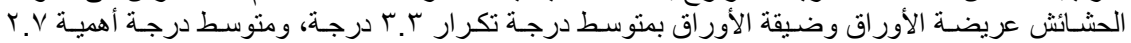

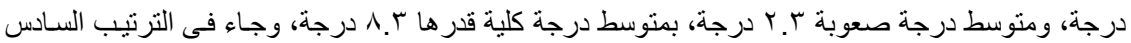

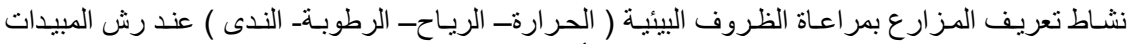

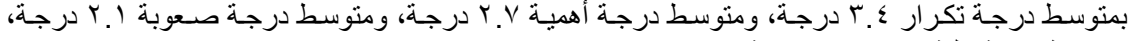

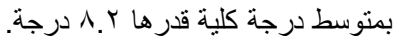

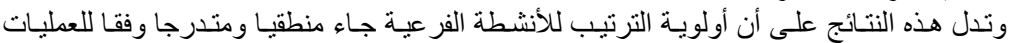

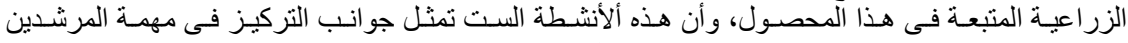

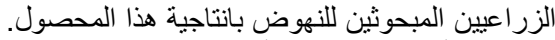

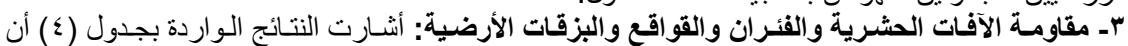

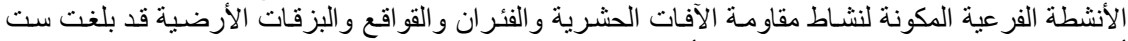

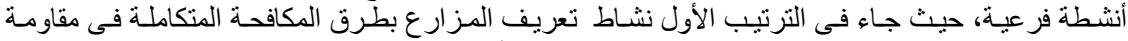

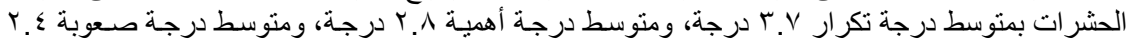

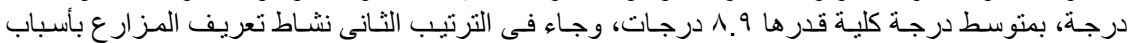

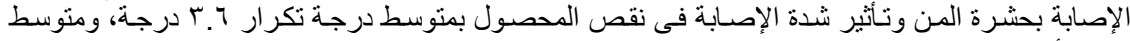

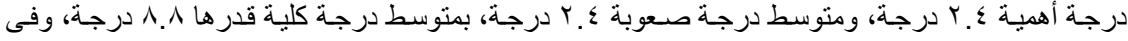

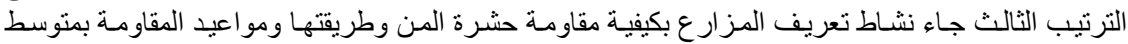

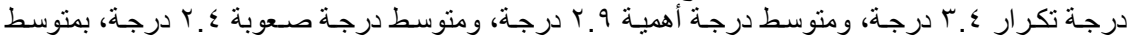

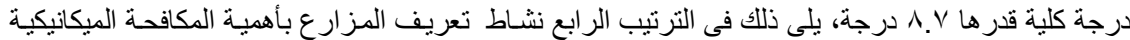

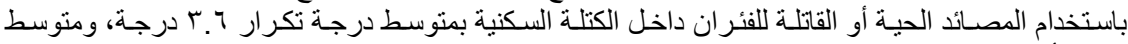

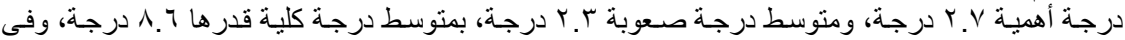

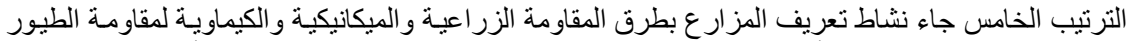

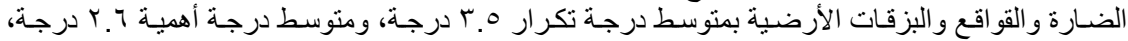

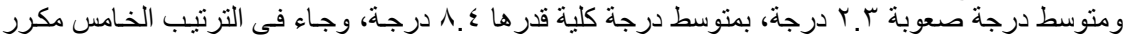

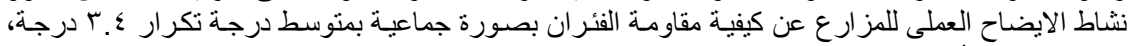

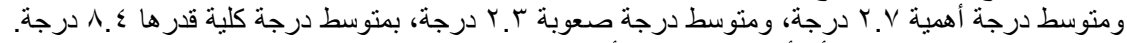

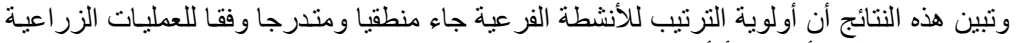

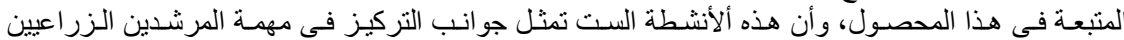
المبحوثين للنهوض هذانتاجية هذا المحصول

جدول رقم (ץ): المتوسطات الحسـابية والاتحر افـات المعياريـة للأنشطة الفرعيـة المكونـة للمهام الارشـادية

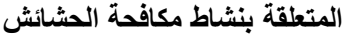

\begin{tabular}{|c|c|c|c|c|c|c|c|c|c|}
\hline التركيز & الترتيب & الارجة متوسة & |الترتيب| & متوسط درجة & الترتيب| & الأهمية & الترتيب & متوسط & الأنشطة الارشادية \\
\hline نعم & 1 & 9.1 & 1 & r.o & 1 & r. 9 & 1 & r.v & |- تعريف المز ارعة بطرق المكافحة الحشائ. \\
\hline نعم & r & 1. 7 & $\varepsilon$ & r.r & ام & r.q & $r$ & r.o & 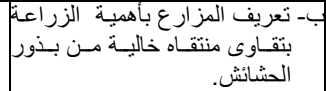 \\
\hline نعم & $\varepsilon$ & ᄉ. $\varepsilon$ & ع & r.r & r & Y.V & r & r.o & 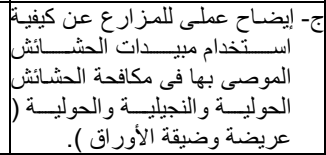 \\
\hline نعم & r & 1. 9 & r & r. $\varepsilon$ & ام & r.q & r & r.7 & 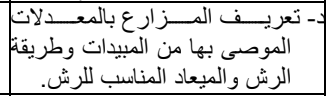 \\
\hline نعم & 7 & $\Lambda . r$ & 0 & r.) & ar & Y.V & $\varepsilon$ & T.ร & 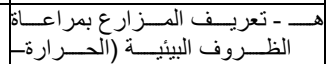 \\
\hline
\end{tabular}




\section{J. Agric. Sci. Mansoura Univ., 34 (10), October, 2009}

\begin{tabular}{|c|c|c|c|c|c|c|c|c|c|}
\hline & & & & & & & & & 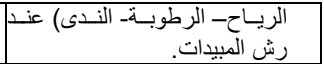 \\
\hline نعم & 0 & $\Lambda . r$ & $r$ & r.r & $a^{r}$ & Y.V & 0 & r.r & 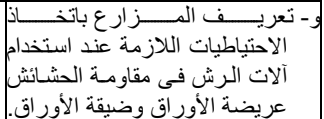 \\
\hline
\end{tabular}

جدول رقم (؛): المتوسطات الحسـابية والاحمرافات المعياريـة للأنثطة الفرعية المكونـة للمهام الارشـادية

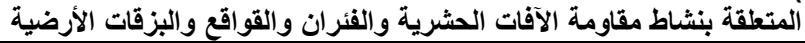

\begin{tabular}{|c|c|c|c|c|c|c|c|c|c|}
\hline التركيز & الترتيب & الارجة الكلية & الترتيب & متوسط درج & الترتيب & متوسط & |الترتيب| & متوسط & الأنشطة الارشادية \\
\hline نعم & 1 & $\wedge .9$ & 1 & r. $\varepsilon$ & 1 & ঙ.^ & 1 & r.v & 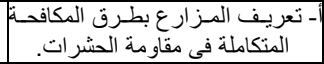 \\
\hline نعم & r & $\wedge . \wedge$ & (1) & T. $\varepsilon$ & ا & r.A & r & $r .7$ & 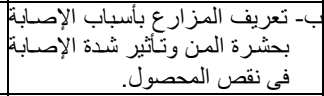 \\
\hline نعم & $r$ & A.V & (5) & $r . \varepsilon$ & ام & r.A & $r$ & r.o & 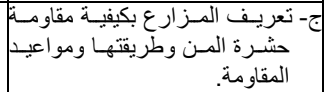 \\
\hline نعم & $5^{0}$ & A. $\varepsilon$ & r & r.r & r & r.V & $\varepsilon$ & r. & 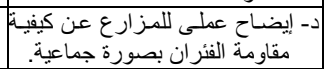 \\
\hline نعم & $\varepsilon$ & ^. 7 & 5t & r.r & r & r.V & r & $r .7$ & 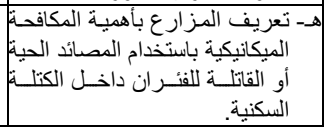 \\
\hline نعم & 0 & A. $\varepsilon$ & 5t & $r . r$ & r & r. 7 & Th & r.o & 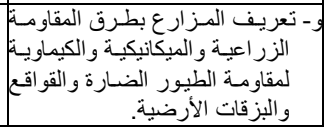 \\
\hline
\end{tabular}

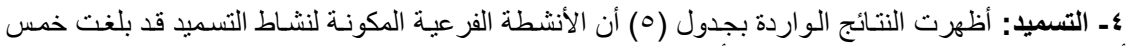

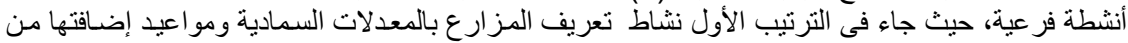

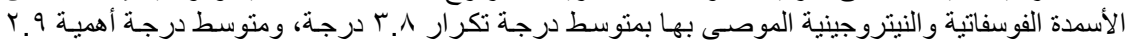

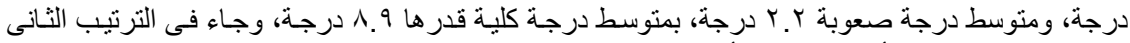

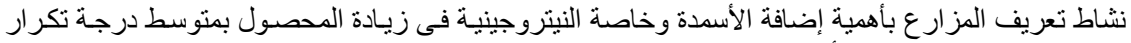

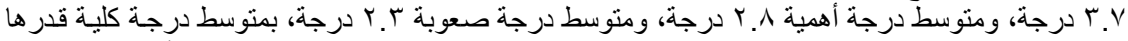

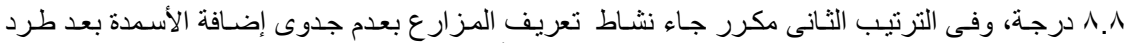

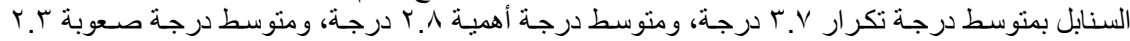

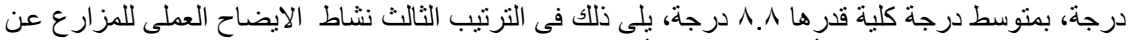

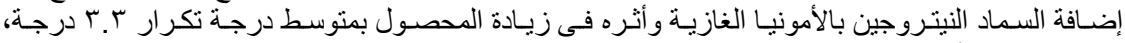

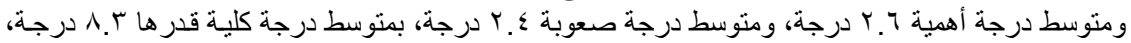

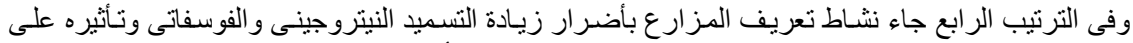

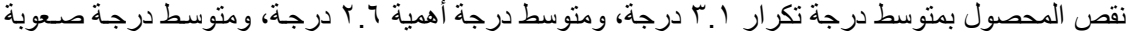

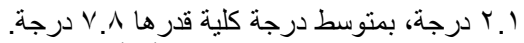

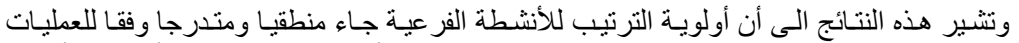

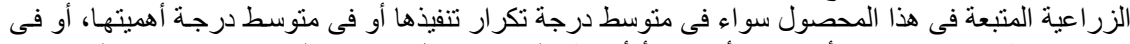

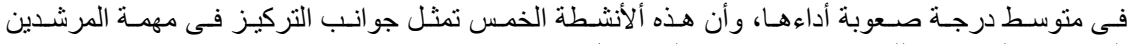

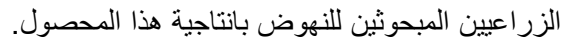

جدول رقم (0): المتوسطات الحسـابية والاتحرافـات المعياريـة للأنشطة الفرعية المكونـة للمهام الارشـادية

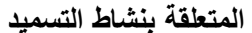

الانشطة الارشّادية


Abd El- Wahab, M. M. ELS.

\begin{tabular}{|c|c|c|c|c|c|c|c|c|c|}
\hline التركيز & & الالارجة & & الصرجية & & الأهرجية & & التكرجة & \\
\hline نعم & r & $\wedge . \wedge$ & r & r.r & r & ¡.^ & r & T.V & 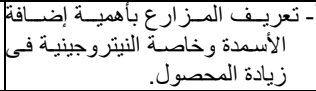 \\
\hline نعم & 1 & 1.9 & $r$ & $r . r$ & 1 & r. .9 & 1 & †.A & 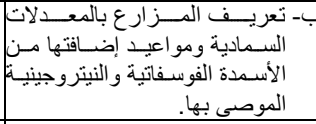 \\
\hline نعم & r & $\wedge . \wedge$ & م & r.r & & r.A & Pr & T.V & 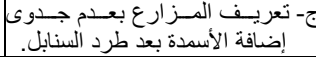 \\
\hline نعم & $\varepsilon$ & A.V & $\varepsilon$ & ఛ.1 & $\varepsilon$ & T. & $\varepsilon$ & r.) & 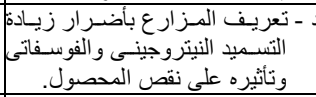 \\
\hline نعم & $r$ & A.r & $r$ & r. & $r$ & T.T & $r$ & r.r & 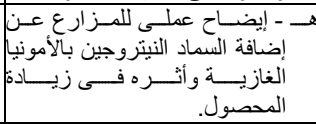 \\
\hline
\end{tabular}

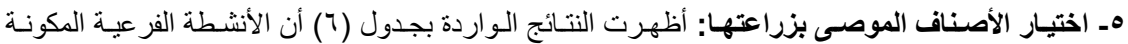

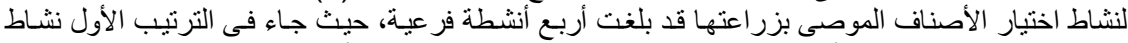

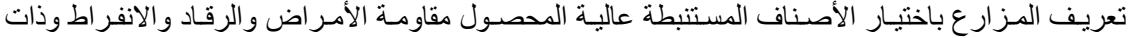

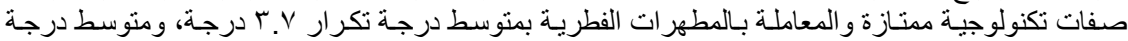

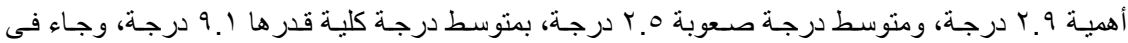

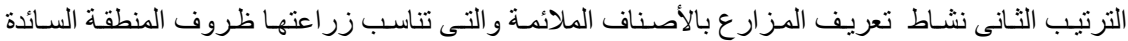

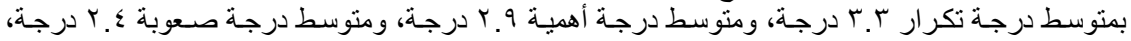

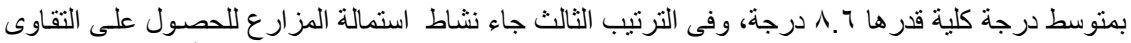

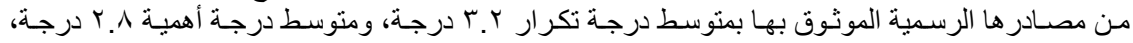

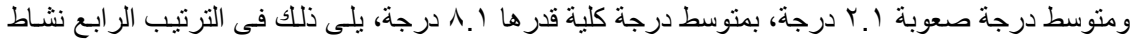

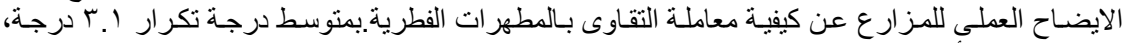

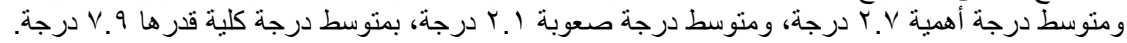

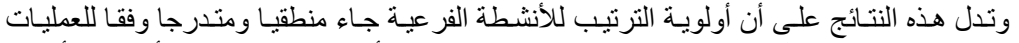

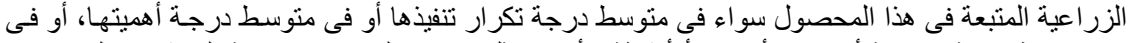

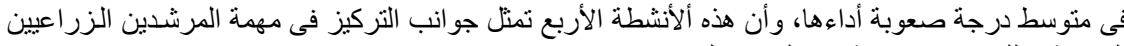

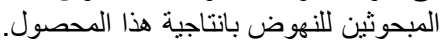

جدول رقم (T): المتوسطات الحسـابية والاتحرافـات المعياريـة للأنثطة الفرعيـة المكونـة للمهام الارشـادية

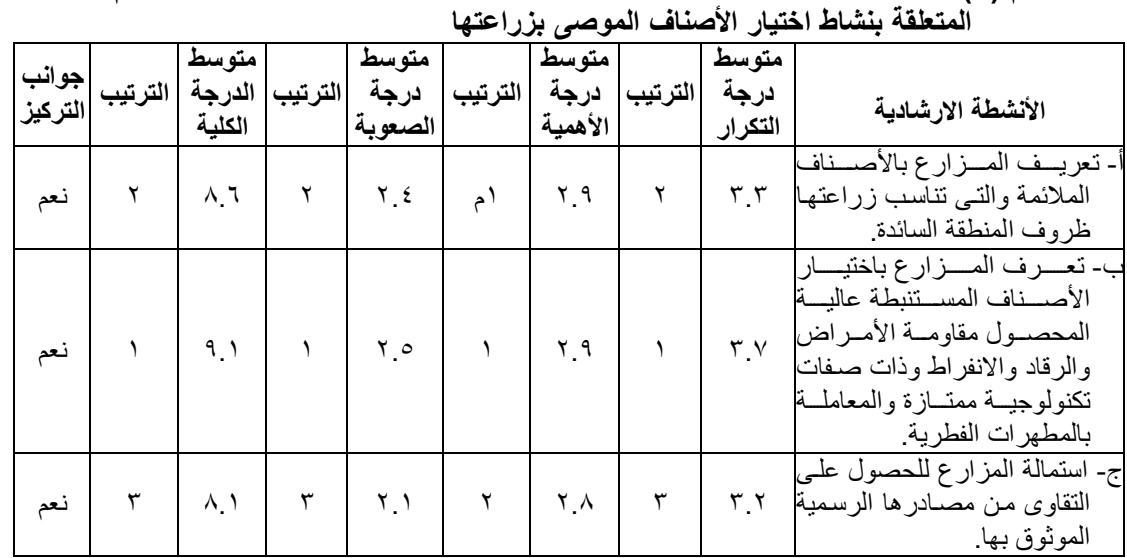

9910 


\section{J. Agric. Sci. Mansoura Univ., 34 (10), October, 2009}

\begin{tabular}{|c|c|c|c|c|c|c|c|c|c|}
\hline نعم & $\varepsilon$ & V.q & r & ૫. & $r$ & T.V & $\varepsilon$ & ז. & 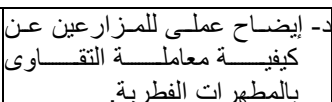 \\
\hline
\end{tabular}

דـ الرى: أظهرت النتائج الواردة بجدول (V) أن الأنشطة الفرعية المكونة لنشاط الرى قد بلغت خمس أنشطة

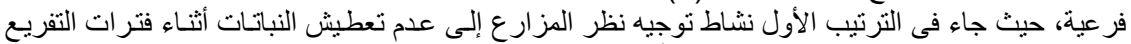

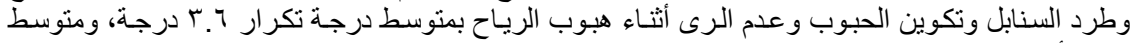

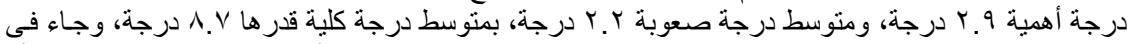

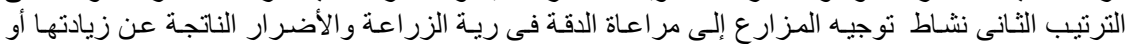

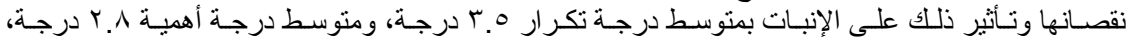

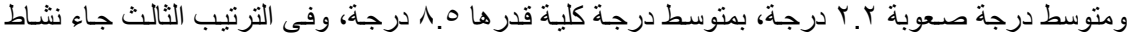

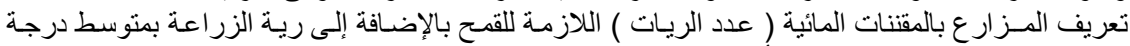

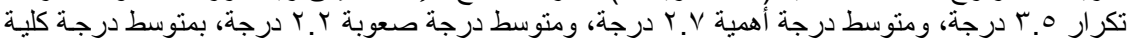

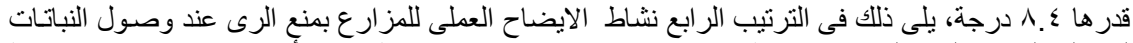

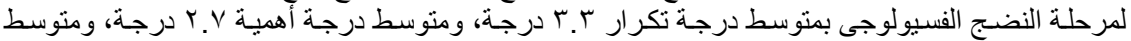

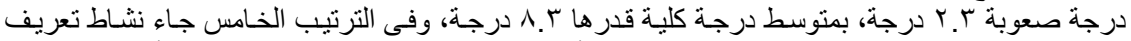

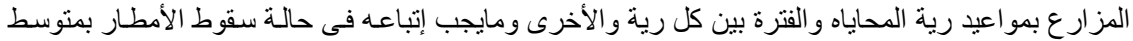

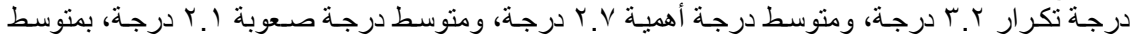

درجة كلية قدر ها · •. د درجة.

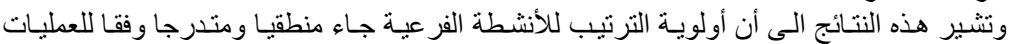

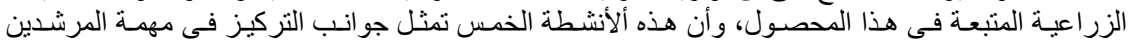
الزراعيين المبحوثين للنهوض بأنتاجية هذا المحصول.

جدول رقم (V): المتوسطات الحسـابية والاتحر افـات المعياريـة للأنشطة الفرعيـة المكونـة للمهام الارشــادية

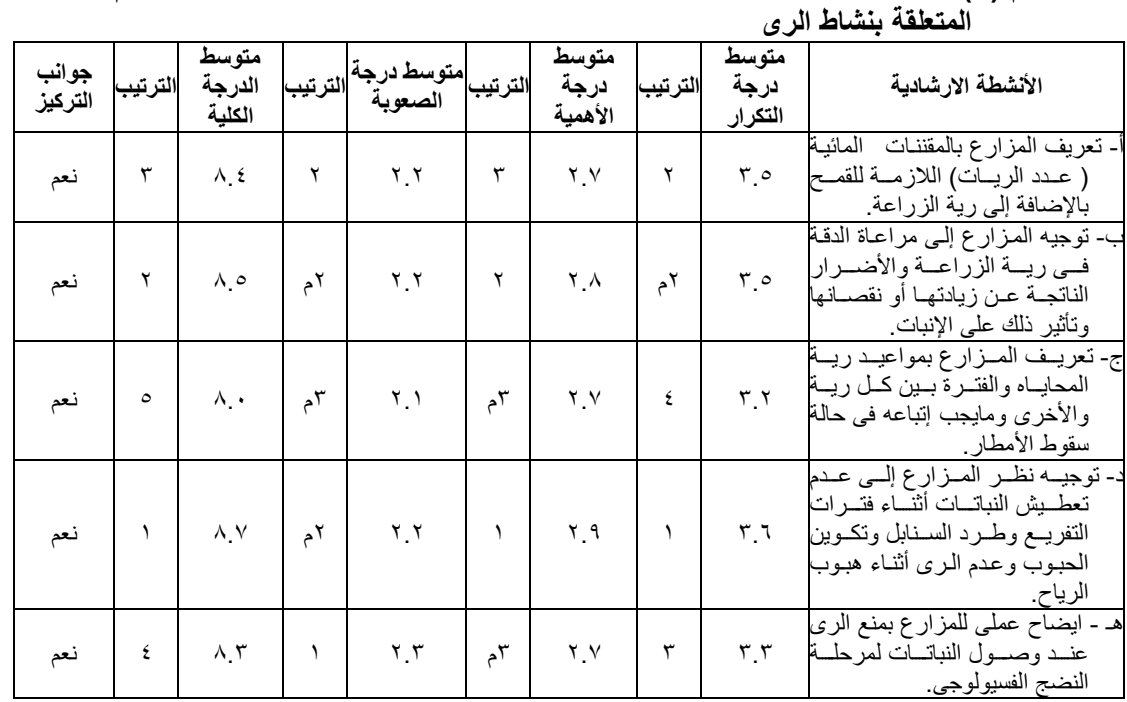

V- طرق الزراعة ومعدل التقاوى : أظهرت النتائج الواردة بجدول (^) أن الأنشطة الفرعيـة المكونـة لنشـاط

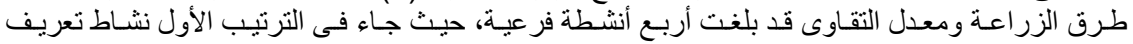

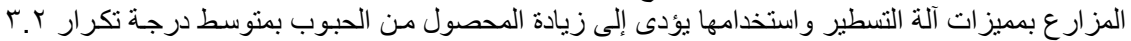

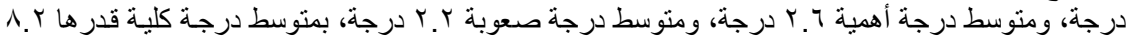


Abd El- Wahab, M. M. ELS.

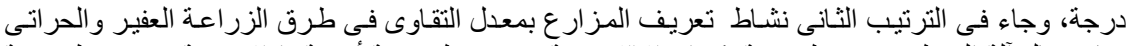

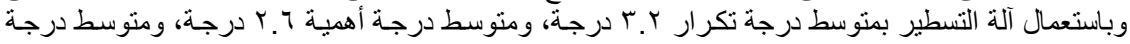

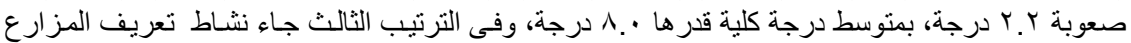

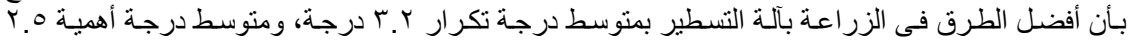

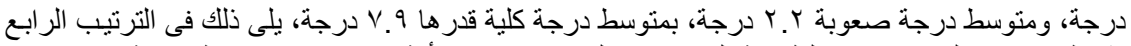

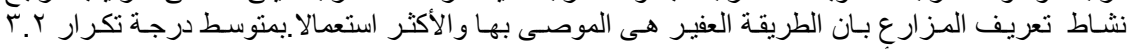

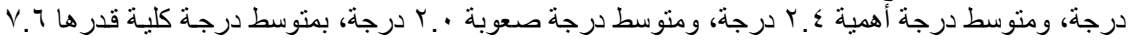

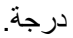

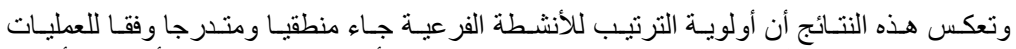

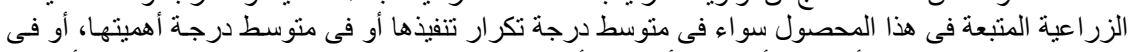

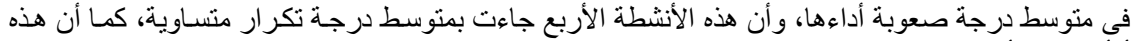

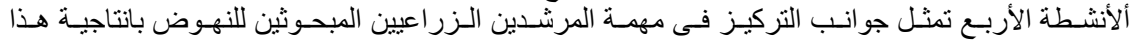

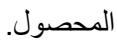
^ـ عمليات الذذمة وميعاد الزراعة: أظهرت النتائج الواردة بجدول (9) أن الأنشطة الفرعية المكونة لنشاط

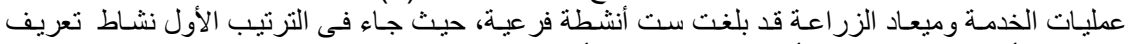

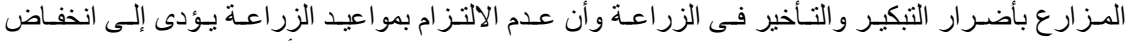

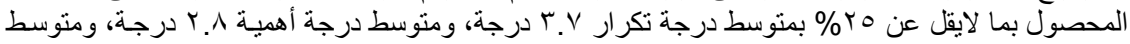

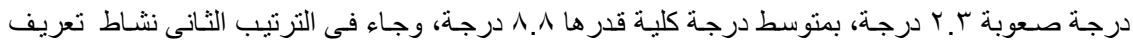

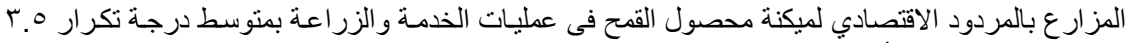

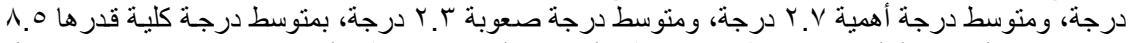

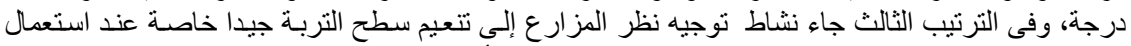

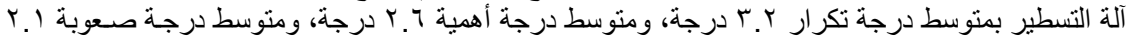

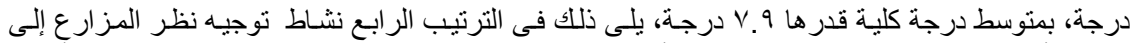

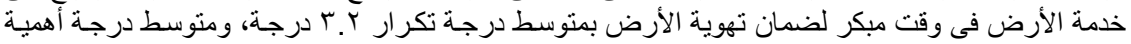

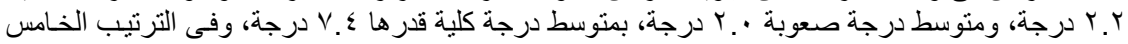

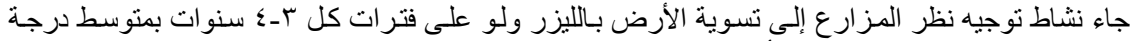

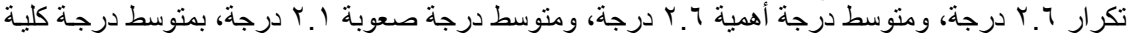

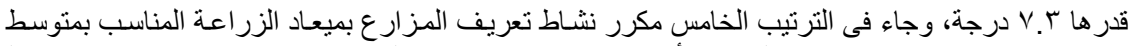

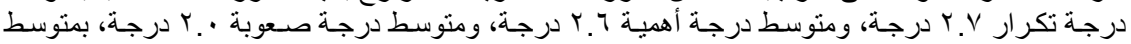

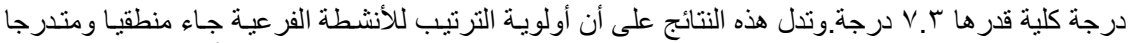

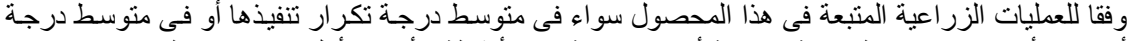

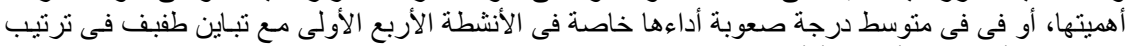

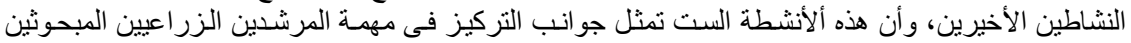

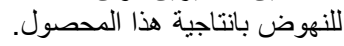

جدول رقم (^): المتوسطات الحسابية والانحرافـات المعيارية للأنثطة الفرعية المكونة للمهام الارشـادية المتعلقة بنشاط طرق الزراعة ومعدل التقاوى التوانية

\begin{tabular}{|c|c|c|c|c|c|c|c|c|c|}
\hline |التركيزب & الترتيب & الكتوسة & |الترتيب | & | لصتوسة & الترتيب & الأهمجية & الترتيب & | لتكرجة & الأنثطة الارشادية \\
\hline نعم & $\varepsilon$ & $v .7$ & r & r. & $\varepsilon$ & r.乏 & 1 & r.r & 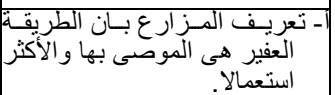 \\
\hline نعم & $r$ & v. .9 & r & Y.r & $r$ & r.o & ام & r.r & 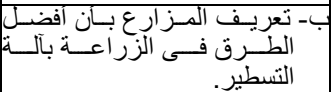 \\
\hline نعم & 1 & A.r & 1 & T.T & 1 & Y. Y & ام & T.r & 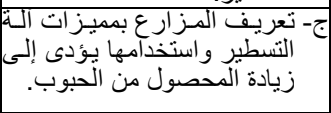 \\
\hline
\end{tabular}


J. Agric. Sci. Mansoura Univ., 34 (10), October, 2009

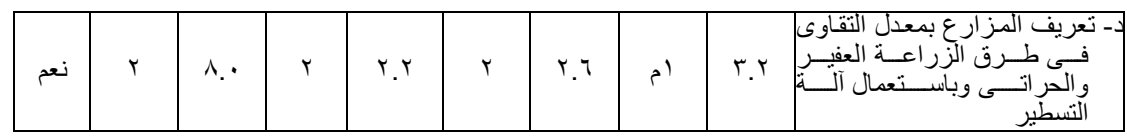

جدول رقم (9): المتوسطات الحسـابية والاتحر افـات المعياريـة للأنثطة الفرعيـة المكونـة للمهـام الارشـادية المتعلقة بنشاط عمليات الخدمة وميعاد الزراعة المراعة المبارية

\begin{tabular}{|c|c|c|c|c|c|c|c|c|c|}
\hline |جتوانب & الترتيب & التوسيط & الترتيب & | لدتوسة & الترتيب & لمتوجة & | الترتيب| & |متوسط درجة & الأنشطة الارشادية \\
\hline نعم & $\varepsilon$ & $V . \varepsilon$ & $\varepsilon$ & $r_{.} \cdot$ & $\varepsilon$ & Y.r & ז'م & $r . r$ & 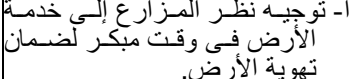 \\
\hline نعم & $r$ & V.q & $r$ & r. 1 & $r$ & Y. & $r$ & $r . r$ & 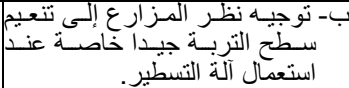 \\
\hline نعم & 。 & V.r & rم & r. 1 & r & r. ${ }^{7}$ & 。 & r.T & 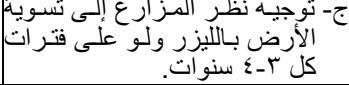 \\
\hline نعم & $5^{0}$ & V.r & ع م & r. & ז'م & Y. & $\varepsilon$ & Y.V & د- المناسبـ المـزارع بميعـاد الزر اعـان \\
\hline نعم & 1 & $\wedge . \wedge$ & 1 & $r . r$ & 1 & r.^ & 1 & T.V & 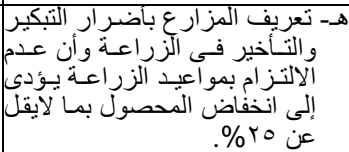 \\
\hline نعم & $r$ & 1.0 & $r$ & r.r & r & Y.V & r & r.o & 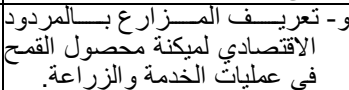 \\
\hline
\end{tabular}

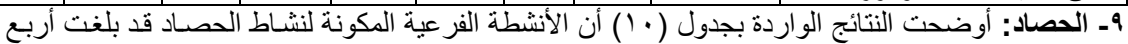

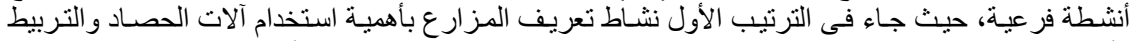

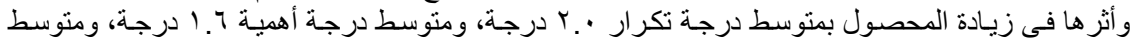

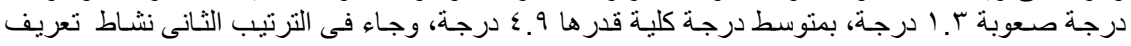

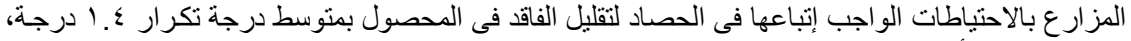

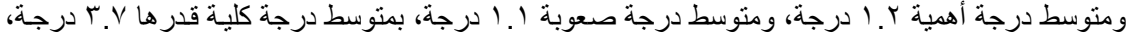

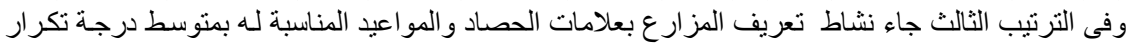

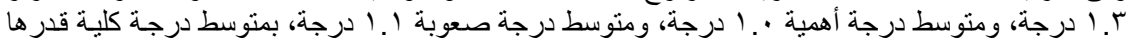

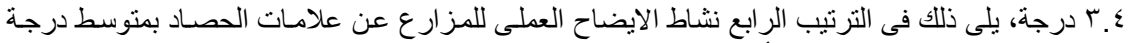

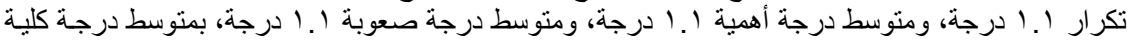

قدرها r.r د درجة.

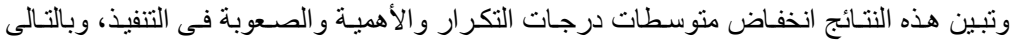

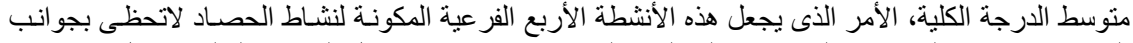

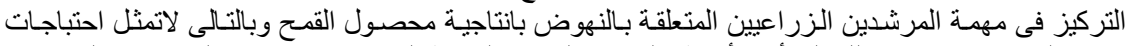

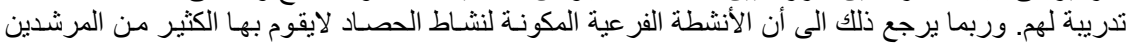

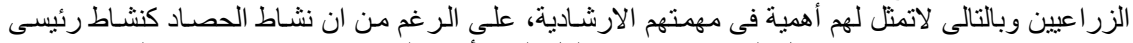

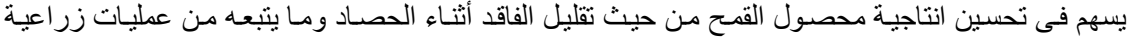

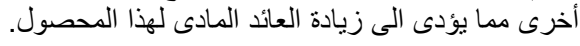

جدول رقم (• (1): المتوسطات الحسـابية والاتحر افـات المعياريـة للأنثطة الفرعية المكونـة للمهام الارشـادية

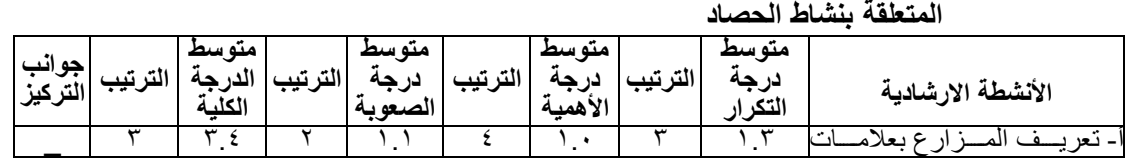


Abd El- Wahab, M. M. ELS.

\begin{tabular}{|c|c|c|c|c|c|c|c|c|c|}
\hline & & & & & & & & & الحصناد و المو اعبد المناسبة له. \\
\hline- & $\varepsilon$ & r.r & r & 1.1 & $r$ & 1.1 & $\varepsilon$ & 1.1 & 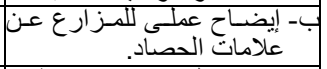 \\
\hline- & r & T.V & r & 1.1 & r & $1 . r$ & r & $1 . \varepsilon$ & 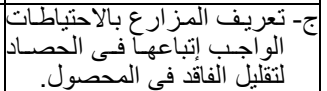 \\
\hline- & 1 & $\varepsilon .9$ & 1 & $1 . r$ & 1 & 1.7 & 1 & r. & 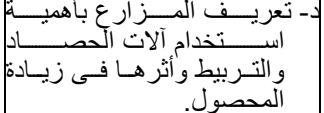 \\
\hline
\end{tabular}

ومن العرض السابق لنتائج تحليل المهمة الارشادية يتضح أن الأنثطة الثمانية الأولى وماتتضمنه

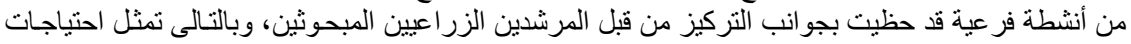

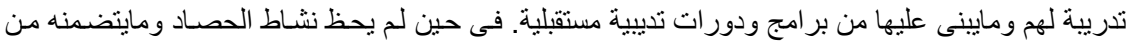

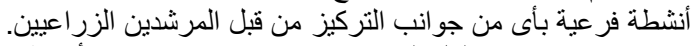

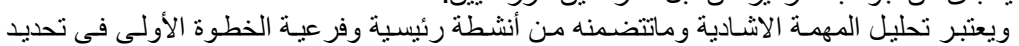

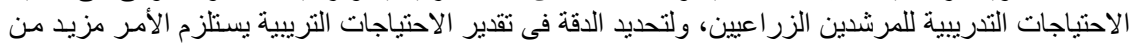

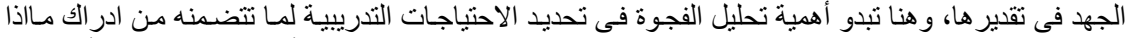

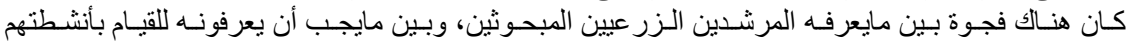

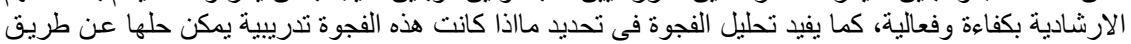
التدريب من عدمه.

ثالثا: تحديد الفجوة بين المستوى الحالى لأداء المرشدين الزراعيين المبحوثين للأنثطة الإرشادية الزراعية

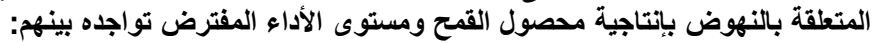

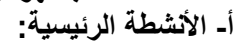

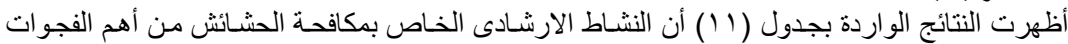

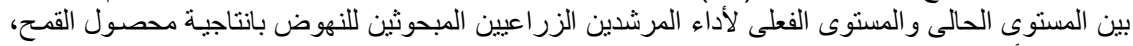

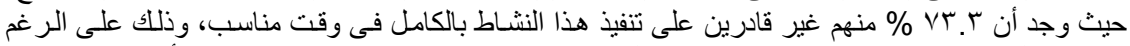

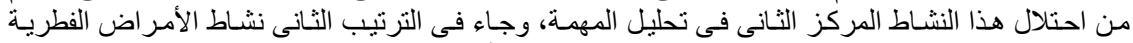

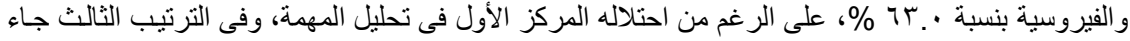

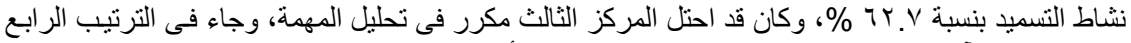

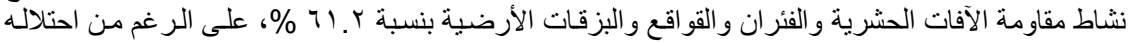

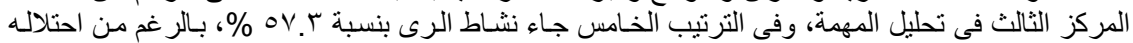

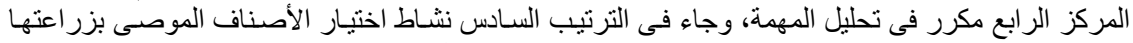

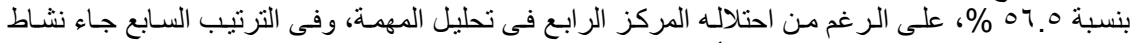

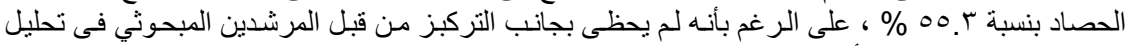

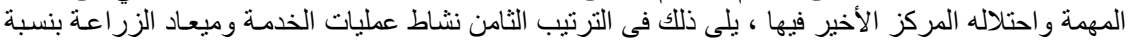

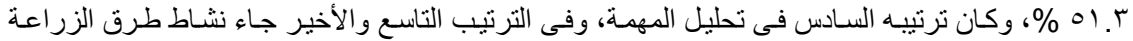

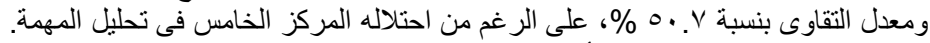

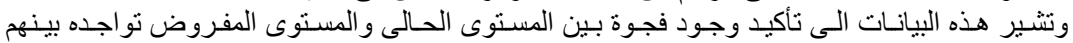

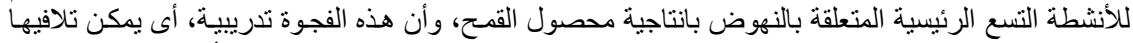

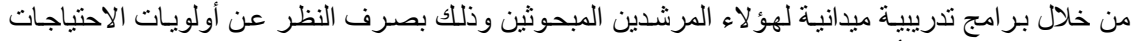

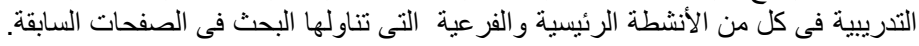

جدول رقم (1 1): النسب المئوية للمستوى الحالى لأداء المرشدين الزراعيين المبحوثين للأنثطة الارشادية

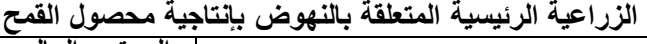

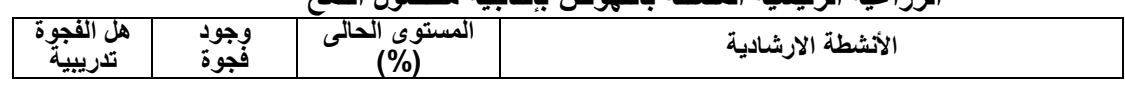




\section{J. Agric. Sci. Mansoura Univ., 34 (10), October, 2009}

\begin{tabular}{|c|c|c|c|}
\hline نعم & نعم & 07.0 & | - اختيار الاصناف الموصى بها وزراعنها \\
\hline نعم & نعم & 01.4 & r ا - عمليات الخدمة وميعاد الزر اعة. \\
\hline نعم & ن ن إم & $0 . . \mathrm{V}$ & آ- طرق الزر اعة ومعدل التقاوى. \\
\hline نعم & ن انعم & OV.Y & 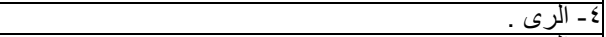 \\
\hline نعم & نعم & Tr. & | 0ـ التسميد. \\
\hline نعم & ن انعم & VT. & 7افحة الحشائش. \\
\hline نعم & ن نعم & $7 . Y$ & V- مقاومة الآفات الحشرية و الفئر ان و القو اقع و البزقات الازرضية. \\
\hline نعم & نعم & 74. & 1ـ الأمر اض الفطرية و الفيروسية. \\
\hline نعم & نعم & 00.4 & 9 - الحصناد . . \\
\hline
\end{tabular}

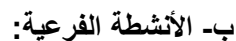

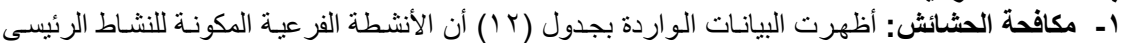

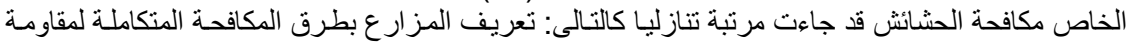

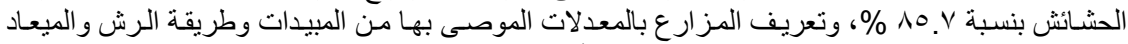

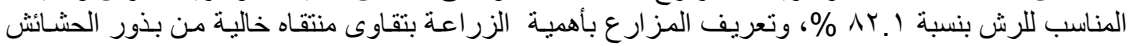

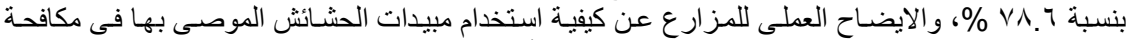

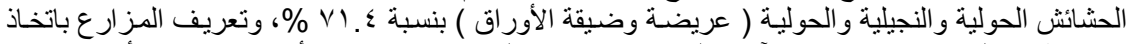

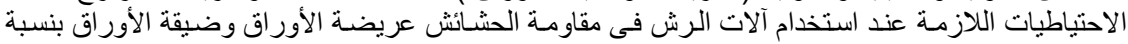

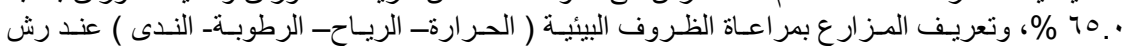

المبيدات بنسبة و . ov\%

جدول رقم (ץ ) إ: النسب المئوية للمستوى الحالى لأداء المرشدين الزراعيين المبحوثين للأنثطة الارشادية

\begin{tabular}{|c|c|c|c|}
\hline تلّريبيةة & وجود فجوة & $\begin{array}{l}\text { المستوي الحالى (\%) } \\
\text { (\%) }\end{array}$ & الأنشطة الارشادية \\
\hline نعم & نعم & $\frac{10.1}{10.1}$ & ـ تعريف المز ارع بطرق المكافحة المتكاملة لمقاومة الحشائش. \\
\hline نعم & نعم & $\mathrm{VA.} . \mathrm{T}$ & 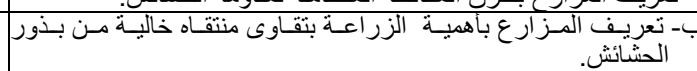 \\
\hline نعم & نعم & VI. & 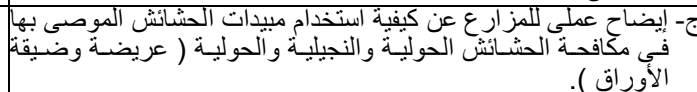 \\
\hline نعم & نعم & Ar. 1 & 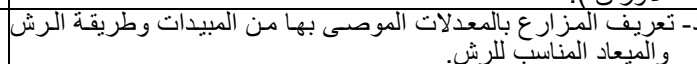 \\
\hline نعم & نعم & 0 o.1 & 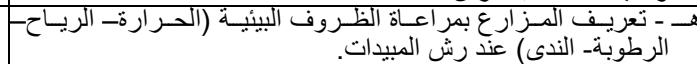 \\
\hline نعم & نعم & 70. & 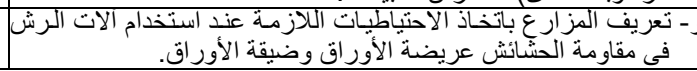 \\
\hline
\end{tabular}

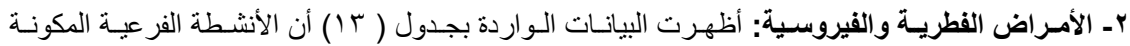

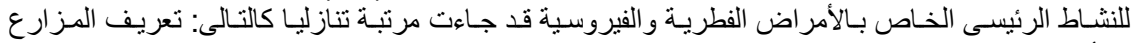

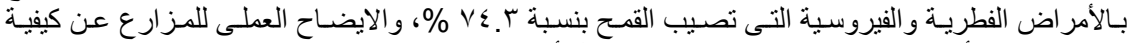

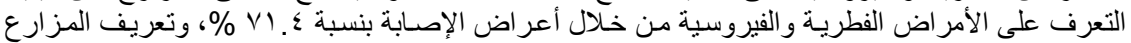

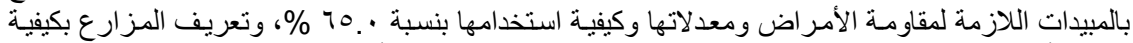

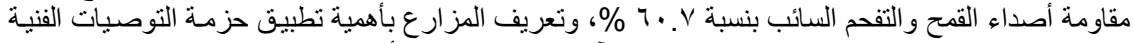

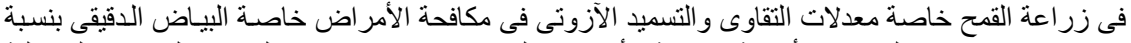

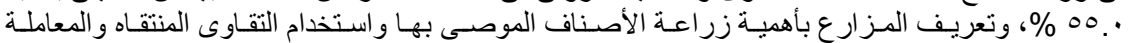

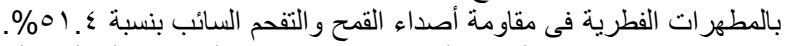

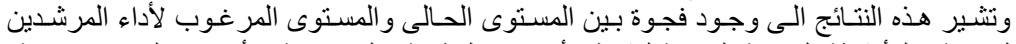
الزراعيين المبحوثين للأنثطة الفرعية الدكونة لنشاط الأمر اض الفطرية والفي والفيروسية، وأن هذه الفجوة تدريبية، ويمكن تقليلها عن طريق الندريب. 
Abd El- Wahab, M. M. ELS.

جدول رقم (r 1): النسب المئوية للمستوى الحالى لأداء المرشدين الزراعيين المبحوثين للأنثطة الارشادية

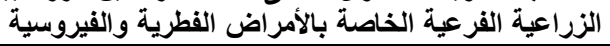

\begin{tabular}{|c|c|c|c|}
\hline 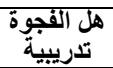 & وفجوة & $\begin{array}{l}\text { المستوى الحالى (\%) } \\
\text { (المالى }\end{array}$ & الأنشطة الارشادية \\
\hline نعر & نعم & $V \leqslant . Y$ & | تعريف المز ارع بالامر اض الفطرية و الفيروسية التى تصيب القمح. \\
\hline نعم & نعم & vi. $\varepsilon$ & 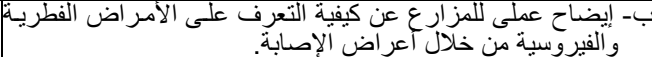 \\
\hline نعم & نعم & $7 \cdot . \mathrm{V}$ & ج- تعريف المز ارع بكيفية مقاومة اصداء القمح و التفحم السائب. \\
\hline نعم & نعم & 70. & 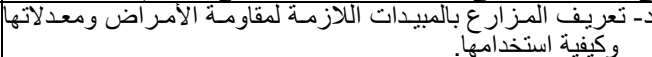 \\
\hline نعم & نعم & $01 . \varepsilon$ & 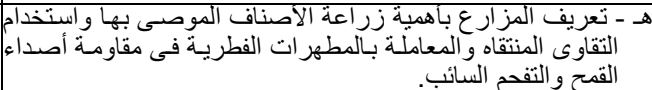 \\
\hline نعم & نعم & 00. & 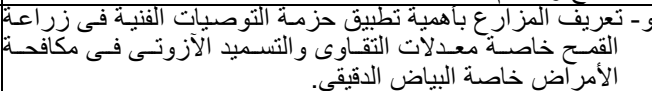 \\
\hline
\end{tabular}

بـــ التسميد: بينت البيانات الواردة بجدول (ع () أن الأنشطة الفرعية المكونة للنشاط الرئيسى الخاص بالتسميد

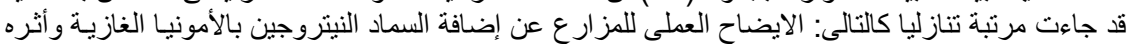

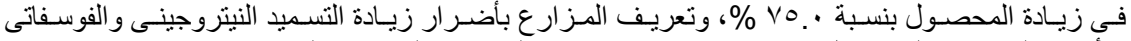

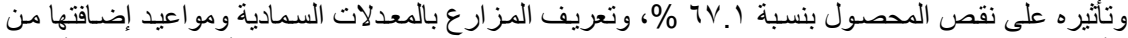

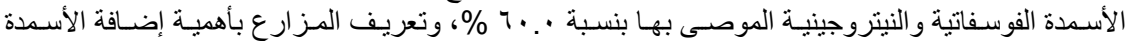

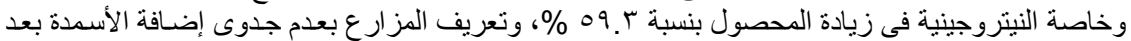

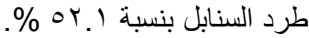

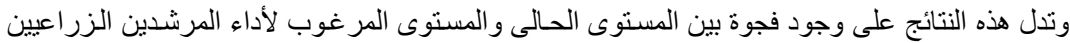

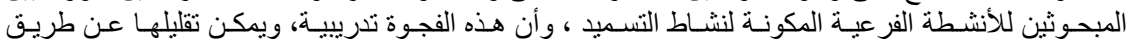

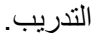

جدول رقم (؛ ( ): النسب المئوية للمستوى الحالى لأداء المرشدين الزراعيين المبحوثين للأنشطة الارشادية الزراعية الفرعية الخاصة بالتسميا لإئاء

\begin{tabular}{|c|c|c|c|}
\hline تلريبية الفوة & وجود فجوة & المستوّى الحالى & الأنشطة الارشادية \\
\hline نعم & نعم & $09 . \mathrm{V}$ & 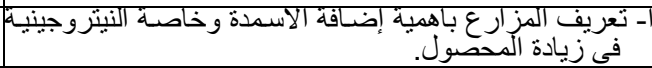 \\
\hline نعم & نعم & $7 \cdot$. & 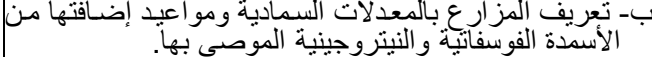 \\
\hline نعم & نعم & Or. 1 & 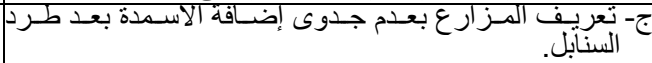 \\
\hline نعم & نعم & $7 V .1$ & 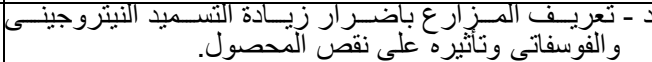 \\
\hline نعم & نعم & vo.. & 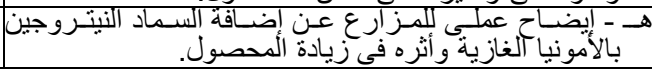 \\
\hline
\end{tabular}

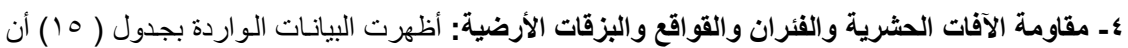

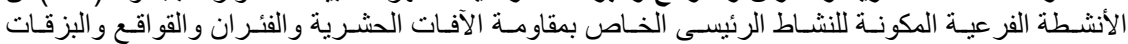

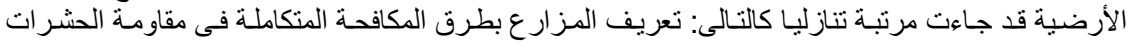

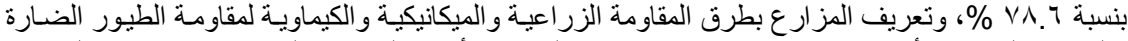

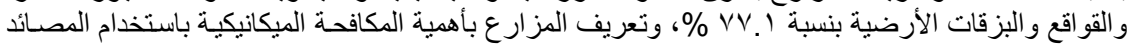

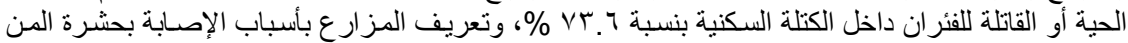

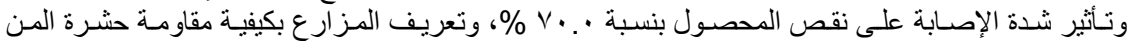

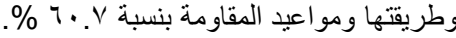




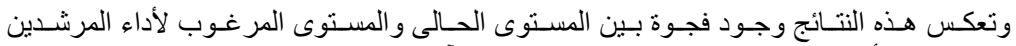

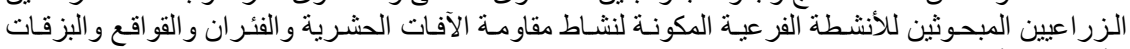

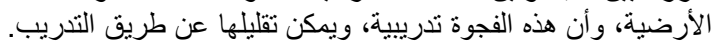

جدول رقم (0 1): النسب المئوية للمستوى الحالى لأداء المرشدين الزراعيين المبحوثين للأنشطة الارشـادية

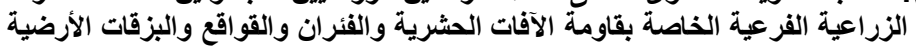

\begin{tabular}{|c|c|c|c|}
\hline تلذريبية الفجوة & وجود فجوة & 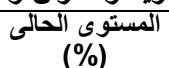 & الأنشطة الارشادية \\
\hline نعم & نعم & $\frac{1}{V A} .7$ & |- تعريف المزار ع بطرق المكافحة المتكاملة فى مقاومة الحشر ات. \\
\hline نعم & نعم & $v \cdot$. & بـ تلىريف المز المصصول. بأباب الإصابة بحشرة المن وتاثيثير شدة الإصـابة \\
\hline نعم & نعم & 71.7 & 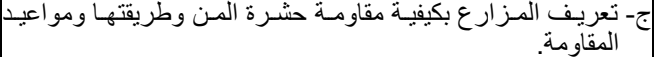 \\
\hline نعم & نعم & $7 \cdot . \mathrm{V}$ & لد- إيضاح عملى للمز ارع عن كيفية مقاومة الفئُ ان بصورة جماعية. \\
\hline نعم & نعم & VT.T & 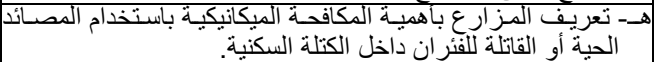 \\
\hline نعم & نعم & VY. 1 & 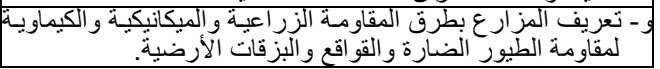 \\
\hline
\end{tabular}

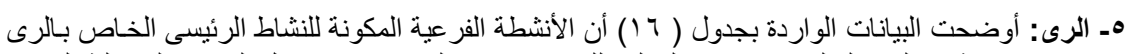

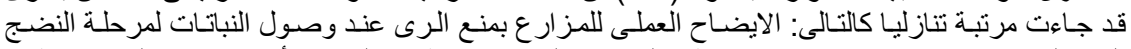

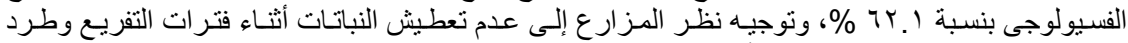

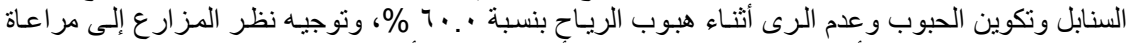

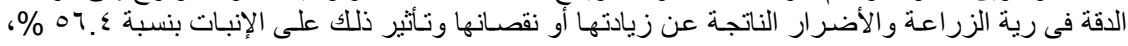

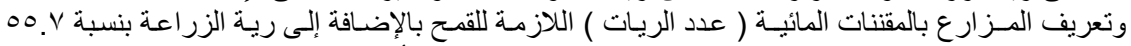

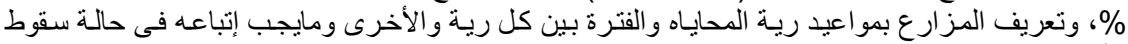

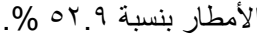

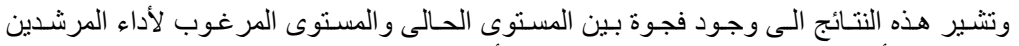

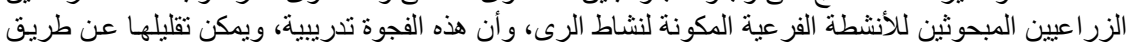
التدريب.

جدول رقم (1 1): النسب المئوية للمستوى الحالى لأداء المرشدين الزراعيين المبحوثين للأنشطة الارشـادية

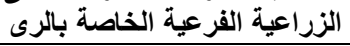

\begin{tabular}{|c|c|c|c|}
\hline تلدريبية & وجود فجوة & 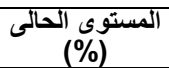 & الأنثطة الارشادية الرئيسية \\
\hline نعم & نعم & $00 . \mathrm{V}$ & 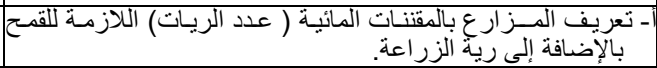 \\
\hline نعم & نعم & or. 9 & 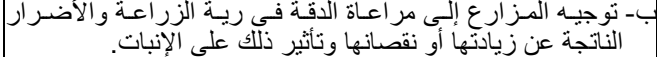 \\
\hline نعم & نعم & $07 . \varepsilon$ & 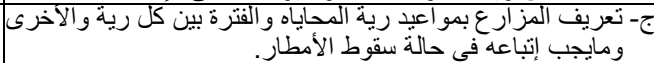 \\
\hline نعم & نعم & $7 .$. & 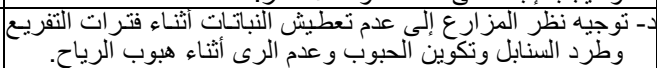 \\
\hline نعم & نعم & Tr.1 & 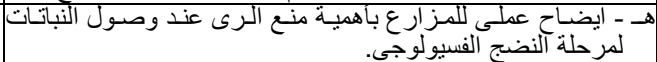 \\
\hline
\end{tabular}

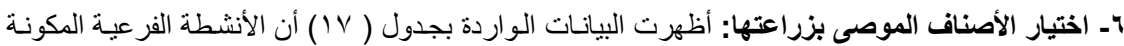

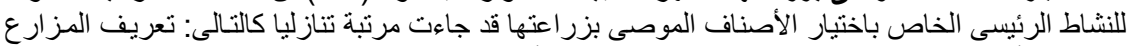

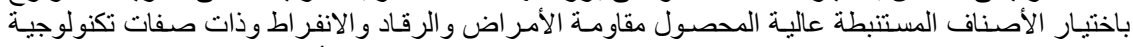

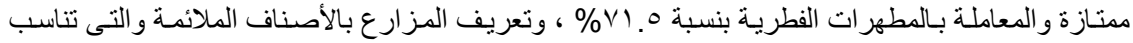

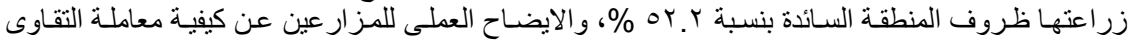

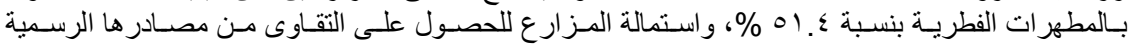

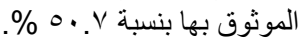


Abd El- Wahab, M. M. ELS.

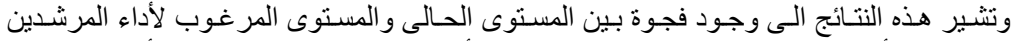

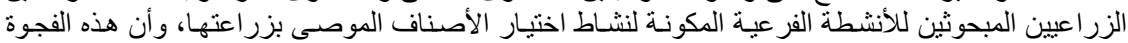
تدريبية، ويمكن تقليلها عن طريق الزين التدريب.

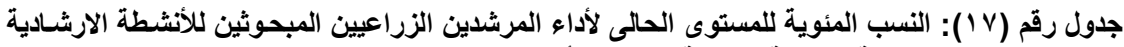

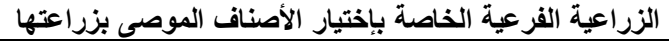

\begin{tabular}{|c|c|c|c|}
\hline تلدريبية & وجود فجوة & $\begin{array}{l}\text { المستوى الحالى (\%) } \\
\text { (\%) }\end{array}$ & الأنشطة الارشـادية الرئيسية \\
\hline نعم & نعم & Or.Y & - تعريفة المز ائرع بالاصناف الملائمة و التى تناسب زر اعتها ظروف \\
\hline نعم & نعم & $V 1.0$ & 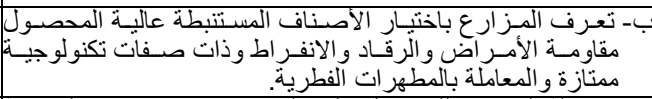 \\
\hline نعم & نعم & $0 . \mathrm{V}$ & 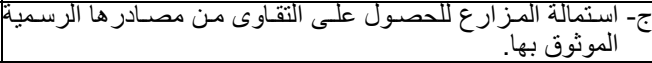 \\
\hline نعم & نعم & $01 . \varepsilon$ & 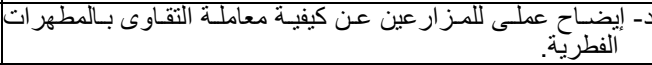 \\
\hline
\end{tabular}

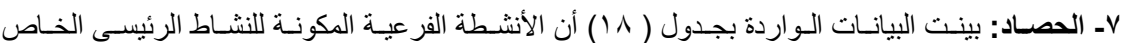

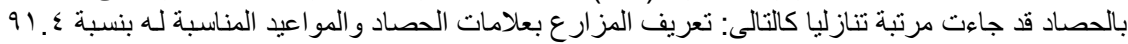

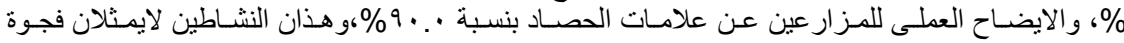

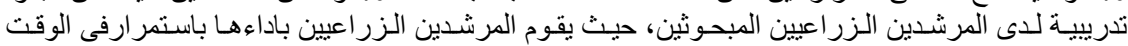

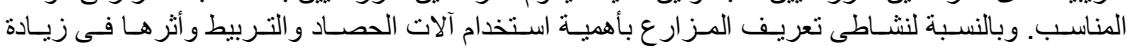

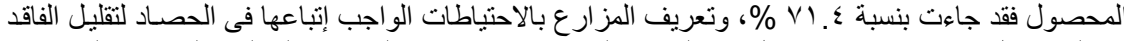

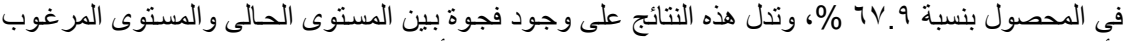

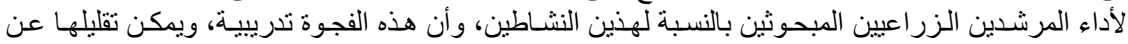
طريق التدريب.

جدول رقم (1 1): النسب المئوية للمستوى الحالى لأداء المرشدين الزراعيين المبحوثين للأنشطة الارشـادية

\begin{tabular}{|c|c|c|c|}
\hline هلي العجونة & وجود فجوة & | المستوي (الحالى| & الأنثطة الارشادية الرئيسية \\
\hline- & - & 41.ร & | - تعريف المز ار ع بعلامات الحصاد والمو اعيد المناسبه له. \\
\hline - & - & $9 \cdot$. & ب- إيضاح عملى للمز اررع عن علامات الحصاد. \\
\hline نعم & نعم & $7 V .9$ & 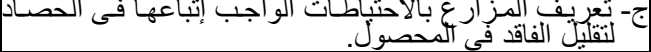 \\
\hline نعم & ن انم & V). 2 & 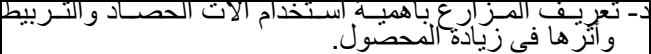 \\
\hline
\end{tabular}

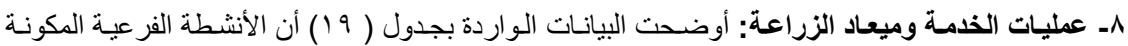

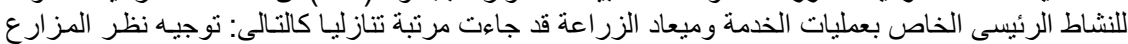

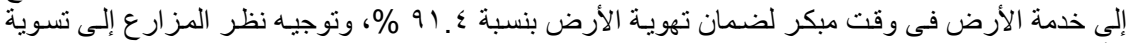

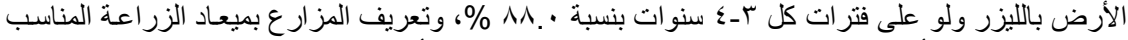

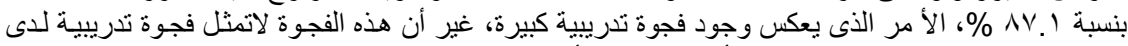

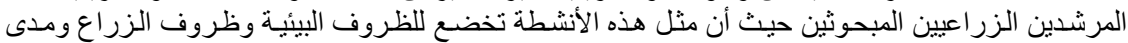

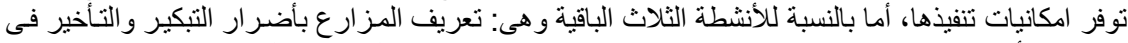

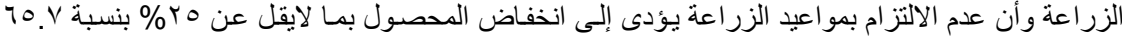

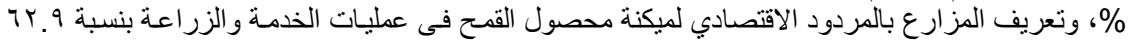

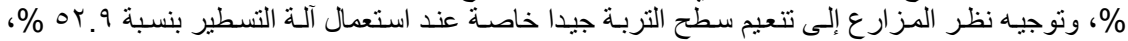

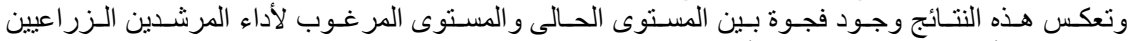

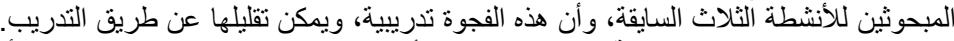

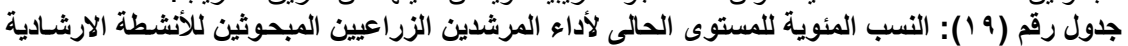

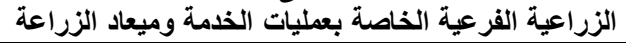

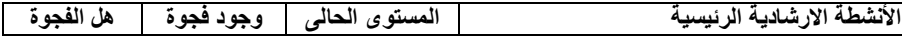


J. Agric. Sci. Mansoura Univ., 34 (10), October, 2009

\begin{tabular}{|c|c|c|c|}
\hline تلاريبية & & $(\%)$ & \\
\hline- & - & $91 . \varepsilon$ & |ـ توجيه نظر المزارع إلى خذمة الأرض فى وقت مبكر لضمان تهوية الأرض. \\
\hline نعم & نعم & Or. 9 & 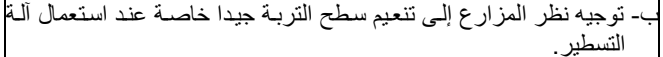 \\
\hline - & - & ^.. & جـ توجيه نظر المزارع إلى تسوية الارض بالليزر ولو على فترات كل ب-ك \\
\hline- & - & Av. 1 & تــ تعريف المز ارع بميعاد الزر اعة المناسب. \\
\hline نعم & نعم & 70. $\mathrm{V}$ & 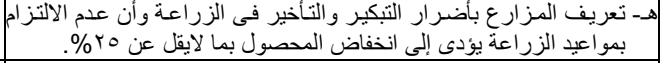 \\
\hline نعم & نعم & TY.9 & 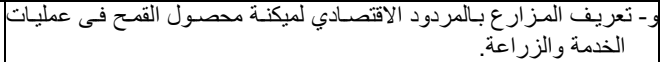 \\
\hline
\end{tabular}

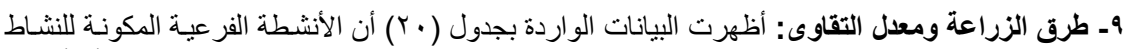

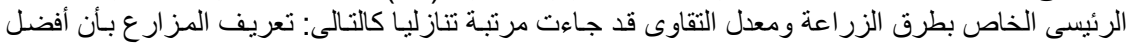

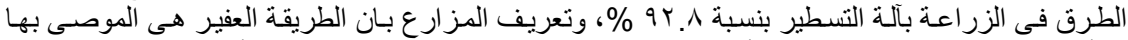

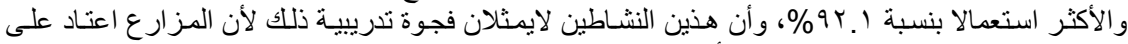

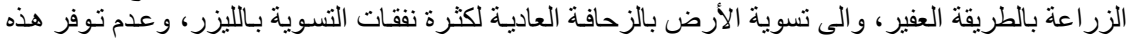

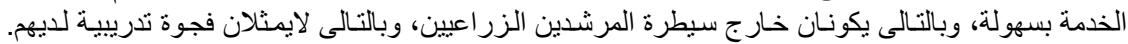

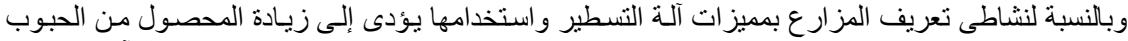

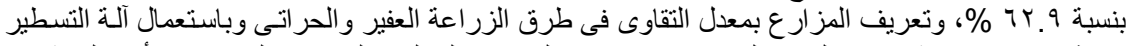

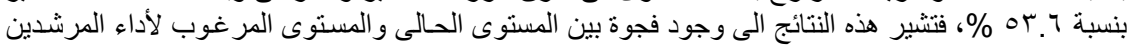

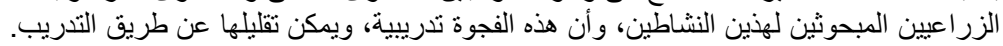

جدول رقم (·ץ): النسب المئوية للمستوى الحالى لأداء المرشدين الزراعيين المبحوثين للأنثطة الارشادية

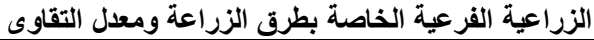

\begin{tabular}{|c|c|c|c|}
\hline تل تل الفجية & وجود فجوة & $\begin{array}{l}\text { المستوى الحالى } \\
\text { (\%) }\end{array}$ & الأنثطة الارشادية الرئيسية \\
\hline- & - & 9.1 & |ـ تعريف المزارع بان الطريقة العفير هى الموصي بها والاكتر استعمالا. \\
\hline - & - & $9 Y .1$ & ب- تعريف المزارع بان افضل الطرق فى الزر اعة بالة التسطير. . \\
\hline نعم & نعم & $\pi .9$ & 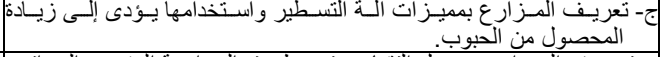 \\
\hline نعم & نعم & or. 7 & 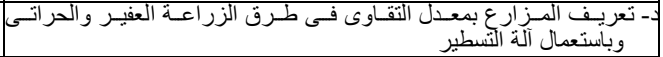 \\
\hline
\end{tabular}

رابعا: بعض الخصائص المميزة للمرشدين الزراعيين المبحوثين:

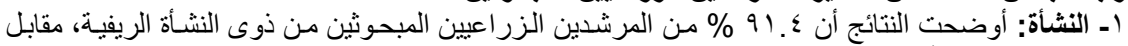

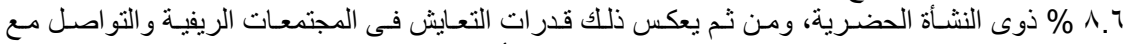

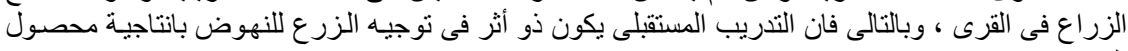
القمح.

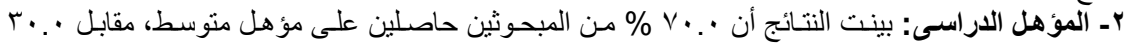

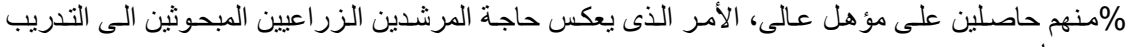

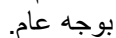

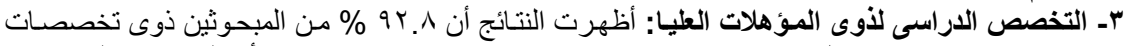

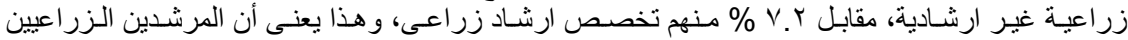

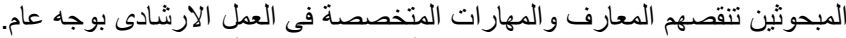

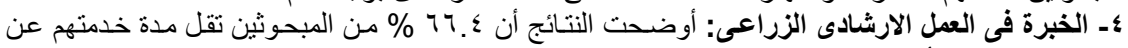

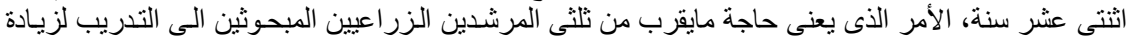

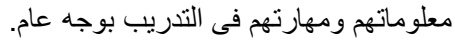

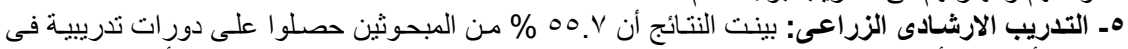

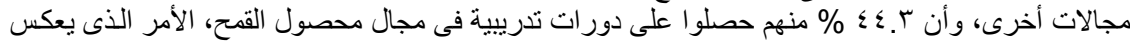

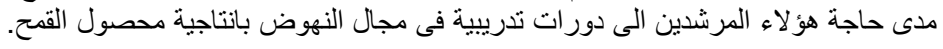


Abd El- Wahab, M. M. ELS.

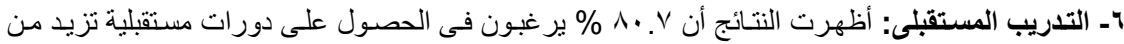

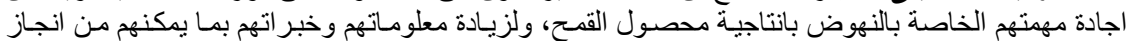

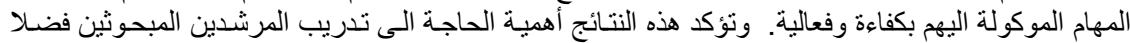

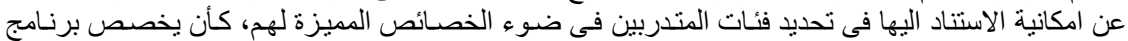

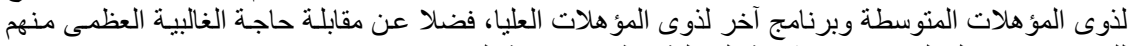

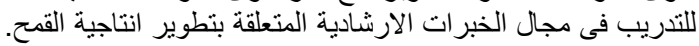

\begin{tabular}{|c|c|c|c|c|c|}
\hline \multicolumn{6}{|c|}{ 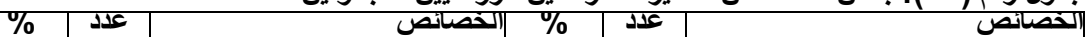 } \\
\hline IV.I & †乏 & 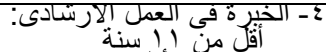 & $91 . \varepsilon$ & $1 \mathrm{r}$ & \\
\hline 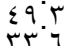 & 79 & 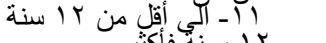 & 1.7 & ir & حضرية \\
\hline$T \cdot \therefore$ & Tहै & المجموع ال المجو & $1 \cdots$ & TE. & 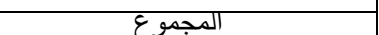 \\
\hline$<\leqslant$ & r & 0- التّريب الإرشادى: التش & $r, r$ & r & ؤهل الدر اسىى: \\
\hline $00 \mathrm{~V}$ & $\vee \wedge$ & في مجالات أخرى الفي مجح & $7 \ddot{\imath}$ & r. & متوسطى \\
\hline $1 \cdots$ & 1E. & المجموع ع & $1 \cdots$ & हा & المجموع \\
\hline$\Lambda . V$ & 114 & آ- الرغبه في التذريب: & $V Y$ & V & 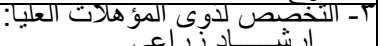 \\
\hline 19.4 & rv & ل الَّير غب & $9 \dot{r} . \wedge$ & 9. & تخصصات أخرى \\
\hline $1 \cdots$ & 1E. & المجموع الموع & $1 \cdots$ & TE. & المجموع المجو \\
\hline
\end{tabular}

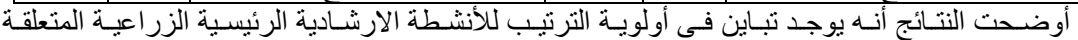

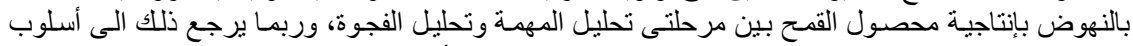

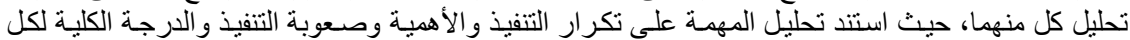

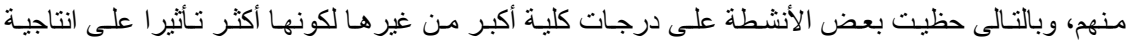

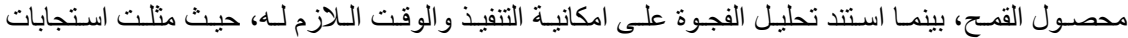

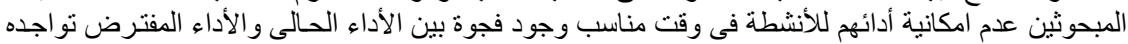

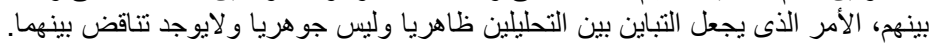

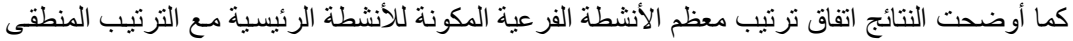

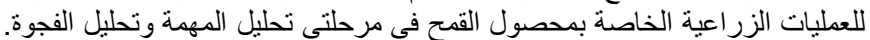

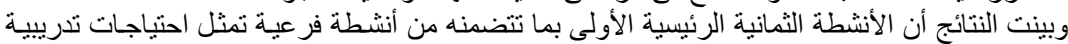

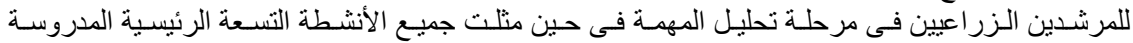

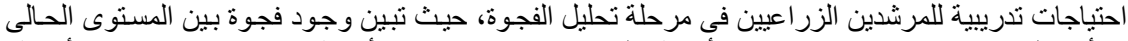

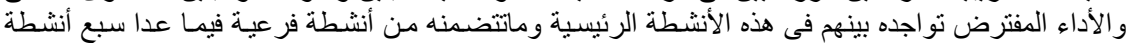

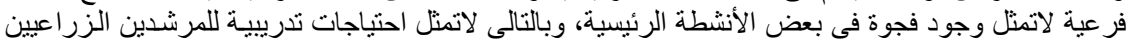
المبحوثين.

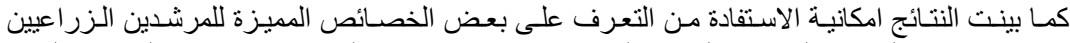

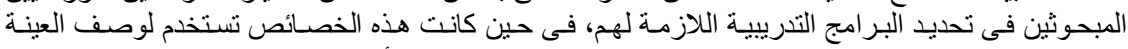

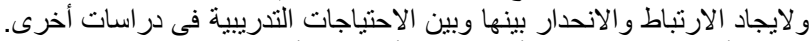

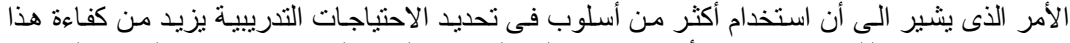

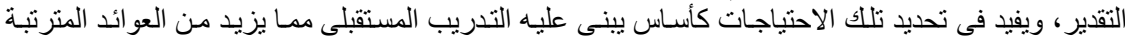

عليه. لللك يوصى الباحث بمايلى:

ا- - ضرورة الاستتاد إلى أكثر من أسلوب في تحديد الاحتياجات التدريبية الارشادية.

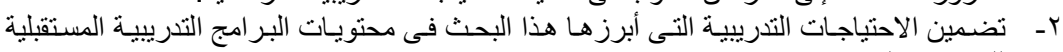
للمرشدين الزر اعيين.

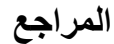

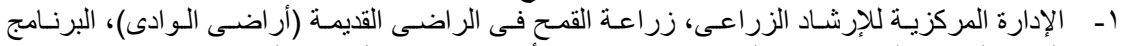

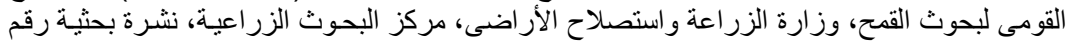




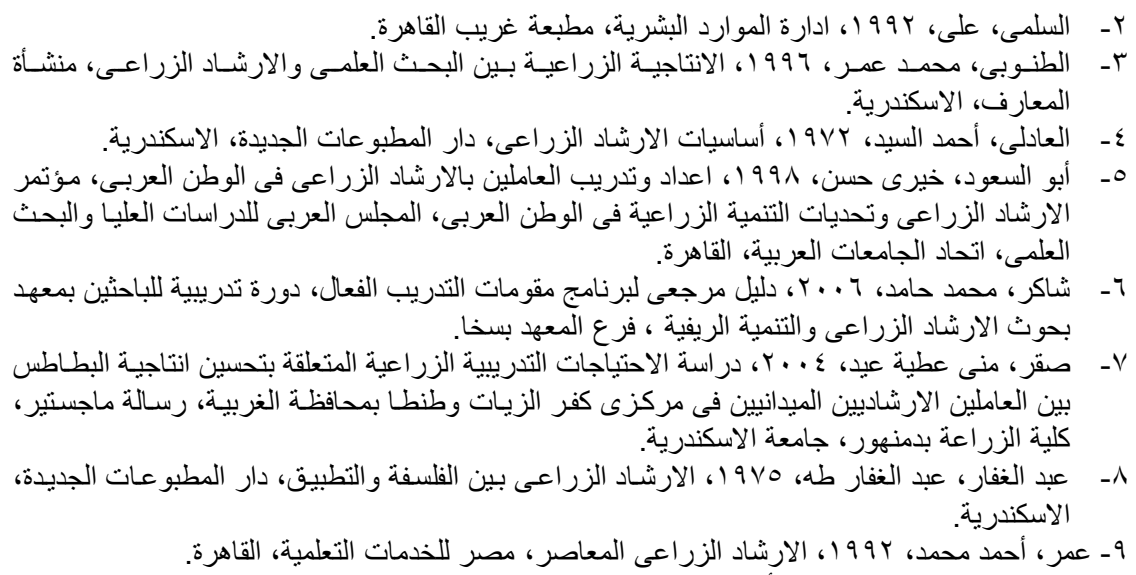

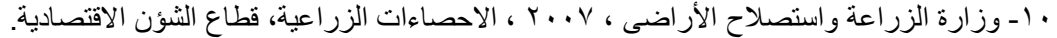
11-Shazly.M.F. (2009) Extension Training and Capacity Development, paper, WWW. Google.com.

12-Raab,Robert,T. and others.1991, Improving Training Quality a Trainer's Guido to Evaluation, Food and Agriculture Organization of the united nation, Roma.

\title{
THE AGRICULTURAL TRAINING NEEDS OF AGRICULTURAL EXTENSION AGENTS REGARDING IMPROVEMENT WHEAT CROP PRODUCTIVITY IN KAFR EL- SHEIKH GOVERNORATE
}

Abd EI- Wahab, M. M. ELS.

Agricultural Extension and Rural Development Research Institute, Agricultural Research Center

\begin{abstract}
This research aims mainly to determine the agriculture training needs of agriculture extension agents regarding improvement wheat crop productivity through the following goals: identify the extension tasks of agricultural extension agents, regarding wheat productivity ranked according to priority, identification of agriculture extension activities, which included in the tasks of agriculture extension agent, ranked according to priority, and identify the gap between the present performed extension activities and the supposed performance to be done by the agriculture extension agents for improvement crop productivity and to identify some the characteristics of agriculture extension agents to be undertaken by the training specialist for developing training programmers to upgrading the performance of agriculture extension agents concerning their task improving crop productivity.

The study was conducted at six districts (Sidi Salim, Kafr EL-sheikh, Alriyadh, Alhamul, Kulain and Desouk) in Kafr EL-Sheikh governorate, Data
\end{abstract}


Abd El- Wahab, M. M. ELS.

were collected through personal interview questionnaire from a random simple amounting to 140 respondents representing about $42.2 \%$ from the total number of the agriculture extension agents in these six chosen districts. And use Arithmetic mean, Standard deviation, beside Frequencies and Percentages in the analysis and presentation of search results. The most important findings were:

- According to the results of the analysis of the tasks outreach activities have included in the tasks of agricultural workers for the advancement of the respondents, the productivity of wheat crop, which have been considered from important from them and their training needs in accordance with the priority as follows: Alaftripulfirosep diseases, control of weeds, and resistance to insect pests rats and snails and Albzqat ground, fertilizing, and the selection of items recommended by the agriculture, irrigation, farming methods and seed rate, and the date of service and agriculture.

- According to the results of the analysis of the gap with extension activities, which involve the training and there is a gap, which are the training needs of agricultural workers respondents in descending order as follows:

The fight against weeds control, diseases Alaftripulfirosep, fertilization, and insect pests, control rats and snails and Albzqat land, irrigation, and the selection of items recommended by the cultivation, harvesting, and the date of service, agriculture, farming methods and seed rate,

- The results of characteristics of agricultural workers: The majority of agents $(91.4 \%)$ have rural origin, This reflects their potentials for living in rural areas and dealing with farmers. (70.0\%) of agents are graduated from secondary agricultural school, and $(92.8 \%)$ of them abstained university degree in majors other than theirs. This show to what extent they are in need to up grading and up dating their capabilities. (66.4\%) of agents have experiences in agricultural extension work in the fields for less than 12 years. $(55.7 \%)$ of them have attended training curses in the other fields. This reflects their potentials the readiness training. (80.7\%) of them expressed their desired to get future training courses to enable to achieve the extension objectives concerning improvement of wheat crop production.

- Recommendations of research: Training needs assessment should be depended on more than one technique or procedure. And The coming training programmes for the field extension agents in the research area should be developed on the light of the needs assessment revealed by this research. 